\title{
Influence of clouds on the spectral actinic flux density in the lower troposphere (INSPECTRO): overview of the field campaigns
}

S. Thiel ${ }^{1}$, L. Ammannato ${ }^{2}$, A. Bais ${ }^{3}$, B. Bandy ${ }^{4}$, M. Blumthaler ${ }^{5}$, B. Bohn ${ }^{6}$, O. Engelsen ${ }^{7}$, G. P. Gobbi ${ }^{2}$, J. Gröbner ${ }^{8, *}$, E. Jäkel ${ }^{9, * * * * * *}$, W. Junkermann ${ }^{1}$, S. Kazadzis ${ }^{3}$, R. Kift ${ }^{10}$, B. Kjeldstad ${ }^{11}$, N. Kouremeti ${ }^{3}$, A. Kylling ${ }^{12, * *}$, B. Mayer ${ }^{13}$, P. S. Monks ${ }^{14}$, C. E. Reeves ${ }^{4}$, B. Schallhart ${ }^{5}$, R. Scheirer ${ }^{13,{ }^{* * *}}$, S. Schmidt ${ }^{9, * * * *}$, R. Schmitt ${ }^{15}$, J. Schreder ${ }^{16}$,

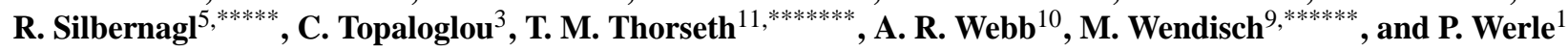

${ }^{1}$ Institut für Meteorologie und Klimaforschung (IMK-IFU), Forschungszentrum Karlsruhe, Garmisch-Partenkirchen, Germany

${ }^{2}$ Istituto di Scienze dell'Atmosfera e del Clima (ISAC-CNR), Consiglio Nazionale delle Ricerche, Rome, Italy

${ }^{3}$ Aristotle University of Thessaloniki, Laboratory of Atmospheric Physics, Thessaloniki, Greece

${ }^{4}$ School of Environmental Sciences, University of East Anglia, Norwich, UK

${ }^{5}$ Division of Biomedical Physics, Innsbruck Medical University, Innsbruck, Austria

${ }^{6}$ Forschungszentrum Jülich, ICG Institut 2: Troposphäre, Jülich, Germany

${ }^{7}$ Norwegian Institute for Air Research (NILU), Polar Environmental Centre, Tromso, Norway

${ }^{8}$ Institute for Health and Consumer Protection (IHCP), Physical and Chemical Exposure Unit, European Comission - Joint

Research Center (JRC), Ispra, Italy

${ }^{9}$ Institute for Tropospheric Research (IFT), Leipzig, Germany

${ }^{10}$ University of Manchester, School of Earth, Atmospheric and Environmental Science, Manchester, UK

${ }^{11}$ Dept. of Physics, Norwegian University of Science and Technology, Trondheim, Norway

${ }^{12}$ Norwegian Institute for Air Research (NILU), Oslo, Norway

${ }^{13}$ Institut für Physik der Atmosphäre, Deutsches Zentrum für Luft- und Raumfahrt (DLR), Oberpfaffenhofen, Germany

${ }^{14}$ Department of Chemistry, University of Leicester, Leicester, UK

${ }^{15}$ Meteoconsult $\mathrm{GmbH}$, Glashütten, Germany

${ }^{16}$ CMS Ing. Dr. Schreder GmbH, Kirchbichl, Austria

*now at: Physikalisch-Meteorologisches Observatorium Davos, World Radiation Center (PMOD/WRC), Dorfstrasse 33, 7260

Davos Dorf, Switzerland

*** now at: St. Olavs Hospital, Trondheim Univ. Hospital, and Alesund Hospital, Alesund, Norway

**** now at: Swedish Meteorological and Hydrological Institute (SMHI), Folkborgsvägen 1, 60176 Norrköping, Sverige

**** now at: University of Colorado, Laboratory for Atmospheric and Space Physics, Duane Physics Building, Room D-337, University of Colorado, Boulder, CO 80309-0311, USA

${ }^{* * * * * *}$ now at: Institut f. Medizinischen Strahlenschutz und Dosimetrie, Landeskrankenhaus Innsbruck, Innrain 66, 6020 Innsbruck

******* now at: Institute for Atmospheric Physics, Johannes Gutenberg-University Mainz, Becherweg 21, 55099 Mainz, Germany

******** now at: Sor Trondelag University College, Faculty of Technology, 7004 Trondheim, Norway

Received: 20 July 2007 - Published in Atmos. Chem. Phys. Discuss.: 13 September 2007

Revised: 11 January 2008 - Accepted: 30 January 2008 - Published: 26 March 2008

Abstract. Ultraviolet radiation is the key factor driving tropospheric photochemistry. It is strongly modulated by clouds and aerosols. A quantitative understanding of the ra-

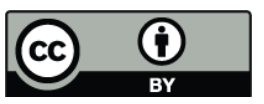

Correspondence to: S. Thiel (stephan.thiel@imk.fzk.de) diation field and its effect on photochemistry is thus only possible with a detailed knowledge of the interaction between clouds and radiation. The overall objective of the project INSPECTRO was the characterization of the threedimensional actinic radiation field under cloudy conditions. This was achieved during two measurement campaigns in Norfolk (East Anglia, UK) and Lower Bavaria (Germany)

Published by Copernicus Publications on behalf of the European Geosciences Union. 
combining space-based, aircraft and ground-based measurements as well as simulations with the one-dimensional radiation transfer model UVSPEC and the three-dimensional radiation transfer model MYSTIC.

During both campaigns the spectral actinic flux density was measured at several locations at ground level and in the air by up to four different aircraft. This allows the comparison of measured and simulated actinic radiation profiles. In addition satellite data were used to complete the information of the three dimensional input data set for the simulation. A three-dimensional simulation of actinic flux density data under cloudy sky conditions requires a realistic simulation of the cloud field to be used as an input for the 3-D radiation transfer model calculations. Two different approaches were applied, to derive high- and low-resolution data sets, with a grid resolution of about $100 \mathrm{~m}$ and $1 \mathrm{~km}$, respectively.

The results of the measured and simulated radiation profiles as well as the results of the ground based measurements are presented in terms of photolysis rate profiles for ozone and nitrogen dioxide. During both campaigns all spectroradiometer systems agreed within $\pm 10 \%$ if mandatory corrections e.g. stray light correction were applied. Stability changes of the systems were below $5 \%$ over the 4 week campaign periods and negligible over a few days. The $\mathrm{J}\left(\mathrm{O}^{1} \mathrm{D}\right)$ data of the single monochromator systems can be evaluated for zenith angles less than $70^{\circ}$, which was satisfied by nearly all airborne measurements during both campaigns. The comparison of the airborne measurements with corresponding simulations is presented for the total, downward and upward flux during selected clear sky periods of both campaigns. The compliance between the measured (from three aircraft) and simulated downward and total flux profiles lies in the range of $\pm 15 \%$.

\section{Introduction}

Ultraviolet radiation is the main driving force of tropospheric photochemistry (Madronich, 1987; Thompson and Stewart, 1991). Tropospheric chemistry is controlled by the photolysis of nitrogen dioxide, ozone, and various other trace gases, and thus by the amount of ultraviolet radiation available throughout the atmosphere and its spectral distribution. The radiation field itself is strongly modulated by clouds and aerosols (Nack and Green, 1974; Mims and Frederick, 1994; Seckmeyer, 1996). Therefore, the interaction of clouds with the radiation field plays a major role in tropospheric chemistry (Madronich, 1987; Lelieveld and Crutzen, 1991; Los et al., 1997; Trautmann et al., 1999). Considering that approximately $60 \%$ of the globe is covered by clouds at any one time, a quantitative understanding of the radiation field and its effect on photochemistry is thus only possible with a detailed knowledge of the interaction of clouds with radiation. This is particularly true for regional and global chemistry models which at present, due to lack of better knowledge, rely on very simple parameterizations of clouds.

While much effort has been expended on the measurement of UV irradiance in ground based networks, on quality assurance issues, and on the improvement of instruments, the interaction of radiation with clouds has not been a main focus, mainly due to a lack of tools to address this important question. The instrumentation and theoretical methods developed during the last decade, however, form the ideal basis for starting research on the effect of clouds on photochemically active radiation. Considerable effort has been spent upon the quality control and to retrieval methodologies for the actinic flux density measurements at the ground (Bais et al., 2003; Webb et al., 2002). The International Photolysis Frequency Measurement and Model Intercomparison (IPMMI) and the ADMIRA project which investigated the relationship between spectral actinic flux density and spectral irradiance were an important step towards a higher level of accuracy of photolysis frequency and spectral downwelling actinic flux density measurements (e.g. Crawford et al., 2003; Webb et al., 2004 ). In addition to the ground based measurement of actinic flux density also several airborne spectroradiometer systems were developed (Hofzumahaus et al., 1999; Shetter and Müller, 1999; Jäkel et al., 2005) and used for first measurements mainly under cloudless conditions. Measured actinic flux density and photolysis frequency profiles exhibit deviations to the 1-D radiation transfer models in UVB at lower altitudes and high aerosol loads even under clear sky conditions (Balis et al., 2002; Hofzumahaus et al., 2002). These deviations are most likely caused by uncertainties in the vertical distribution of aerosols and surface characteristics (Hofzumahaus et al., 2002), however experimental uncertainties may also have an impact, especially at low altitudes.

The most challenging and important task is the characterization of the radiation field under cloudy conditions so as to be representative of larger areas of $50 \times 50 \mathrm{~km}^{2}$. This corresponds to the size of a typical grid cell of a Chemical Transport Model (CTM) and allows thus the investigation of the impact of the variability of the actinic flux density due to clouds on photochemistry on a statistical basis. Clouds are usually variable in all three spatial dimensions, thus requiring three-dimensional rather than one-dimensional radiative transfer simulations. Secondly, the experimental characterization of a three-dimensional cloud field is a demanding task, requiring at least the instantaneous determination of extinction coefficient throughout the cloud field. Single aircraft instrumentation can only provide cross sections at the time and location of the measurement and thus needs to be complemented by further aircraft and ground-based measurements as well as satellite data.

The main task of the INSPECTRO-project was the investigation of the influence of clouds on the spectral actinic flux density in the lower troposphere. This project brought together state of the art measurement and modelling 
capabilities and combined them in an innovative approach to study the three-dimensional radiation field.

- ground-based instrumentation for measurements of spectrally resolved actinic flux density and irradiance as well as some properties of aerosols and clouds.

- airborne instrumentation to characterize the vertical distribution of the spectral actinic flux density as well as cloud parameters and the optical properties of the cloudfree areas.

- Satellite based information of cloud cover and total ozone column over the measurement area.

This paper provides an overview and summary of the INSPECTRO field campaigns in 2002 in East Anglia, UK and 2004 in Bavaria, Germany and describes the measurement sites and conditions as well as the spectral actinic flux density measurement systems. We present results of the intercomparison of the participating spectroradiometers, the comparison of airborne measurements from different platforms and ground based measurements as well as the validation of simulated cloud fields (Scheirer and Schmidt, 2005; Schmidt et al., 2007) as input for 3-D radiation transfer models. The paper is part of a special issue within ACP and forms a reference for other publications utilising data from the INSPECTRO campaigns as it contains detailed description of the campaign site, prevailing conditions, instrumentations, data collection and simulations.

In numerous publications a clear distinction between "flux" and "flux density" is not consequently made. Since more than 2 decades it is rather common to use the term of "flux" (the unit of the radiant flux is $\mathrm{J} \mathrm{s}^{-1}$ or $\mathrm{W}$ ) in cases where clearly a "flux density" (unit $\mathrm{W} \mathrm{m}^{-2}$ ) is described. We have decided to choose the correct term "actinic flux density" throughout the entire manuscript, instead of the shorter and unfortunately more widespread (though incorrect) term "actinic flux".

\section{Experimental}

The first campaign was performed in East Anglia (Norfolk, UK) from 1 September until 1 October 2002. The second campaign was performed in the South East of Bavaria (Straubing, Germany) between 3 and 28 May 2004. While the area of East Anglia is strongly influenced by a maritime climate, the Bavarian area represents a continental climate site in Europe.

\subsection{Measurement sites}

\section{East Anglia}

Ground based instruments were deployed at four sites, marking the corners of the experimental box with an area of approximately $12 \times 20 \mathrm{~km}^{2}$. The geographical position of the sites as well as the topography of the area is shown in Fig. 1. Each site was equipped with a cabin housing the personnel and control computers. The instruments were mounted either on the ground close to the cabins, or on a cabin roof. The Weybourne site (WE, $20 \mathrm{~m}$ a.s.l.) is a field station of the University of East Anglia with routine chemical measurements so this was used as the core site with both chemistry and radiation data available. The site is on the coast, with the permanent Weybourne buildings closest to the sea, then a gently sloping concrete area, finally grass closest to inland (to the south). The other sites were at Beeston Regis (BE, $20 \mathrm{~m}$ a.s.l.) on top of the cliff, to the east of Weybourne; at a school in Briston (BR, $70 \mathrm{~m}$ a.s.1.), inland to the south and slightly west of Weybourne; and at Aylsham (AY, $30 \mathrm{~m}$ a.s.l.), inland to the south of Beeston Regis. Norwich airport (NO, $33 \mathrm{~m}$ a.s.l.), where the aircraft were based, is to the South East of this grid.

\section{Bavaria}

For the Bavarian campaign the ground based instruments were deployed at six sites shown in Fig. 1 (Bavaria, Germany) and covering an area of approximately $55 \times 55 \mathrm{~km}^{2}$. The topography of the Bavarian campaign area is much more pronounced than in East Anglia and ranges from $320 \mathrm{~m}$ a.s.l. at Straubing airport (ST) up to $1030 \mathrm{~m}$ a.s.l. on top of the Brotjacklriegel mountain (BJ). The site at Buchhofen (BU, $338 \mathrm{~m}$ a.s.1.) was centred in the measurement area and was used as the core site. Spiegelau (SP) is a site with an altitude of $830 \mathrm{~m}$ a.s.l. in the mountain area. On top of the mountain Brotjacklriegel the Federal Environmental Agency (UBA, Dessau, Germany) has operated a recording point for air quality. It was used as a "high elevation" site for spectral actinic flux density measurements. However, this site was adversely affected by obstructions of the horizon. In addtition the three airports at Fürstenzell (FU, $410 \mathrm{~m}$ a.s.l.), Eggenfelden (EG, $411 \mathrm{~m}$ a.s.l.) and Straubing were used in the corners of the measurement grid. The airfield of Straubing in the North East of the grid was used as an operational base for the aircraft. The surroundings for most sites consisted of a mixture of grass-, farm- and woodland. As in East Anglia, each site was equipped with a cabin housing the personnel and control computers for the instrumentation at the site.

\subsection{Measurement platforms and airborne instrumentation}

The following airborne platforms were used during both campaigns:

- A Cessna (C) for measuring ground albedo (East Anglia and Bavaria) and spectral actinic flux density below clouds (Bavaria)

- Two Partenavia P68 (PG and PL) for measuring albedo (ground and clouds, only PL), spectral actinic flux 

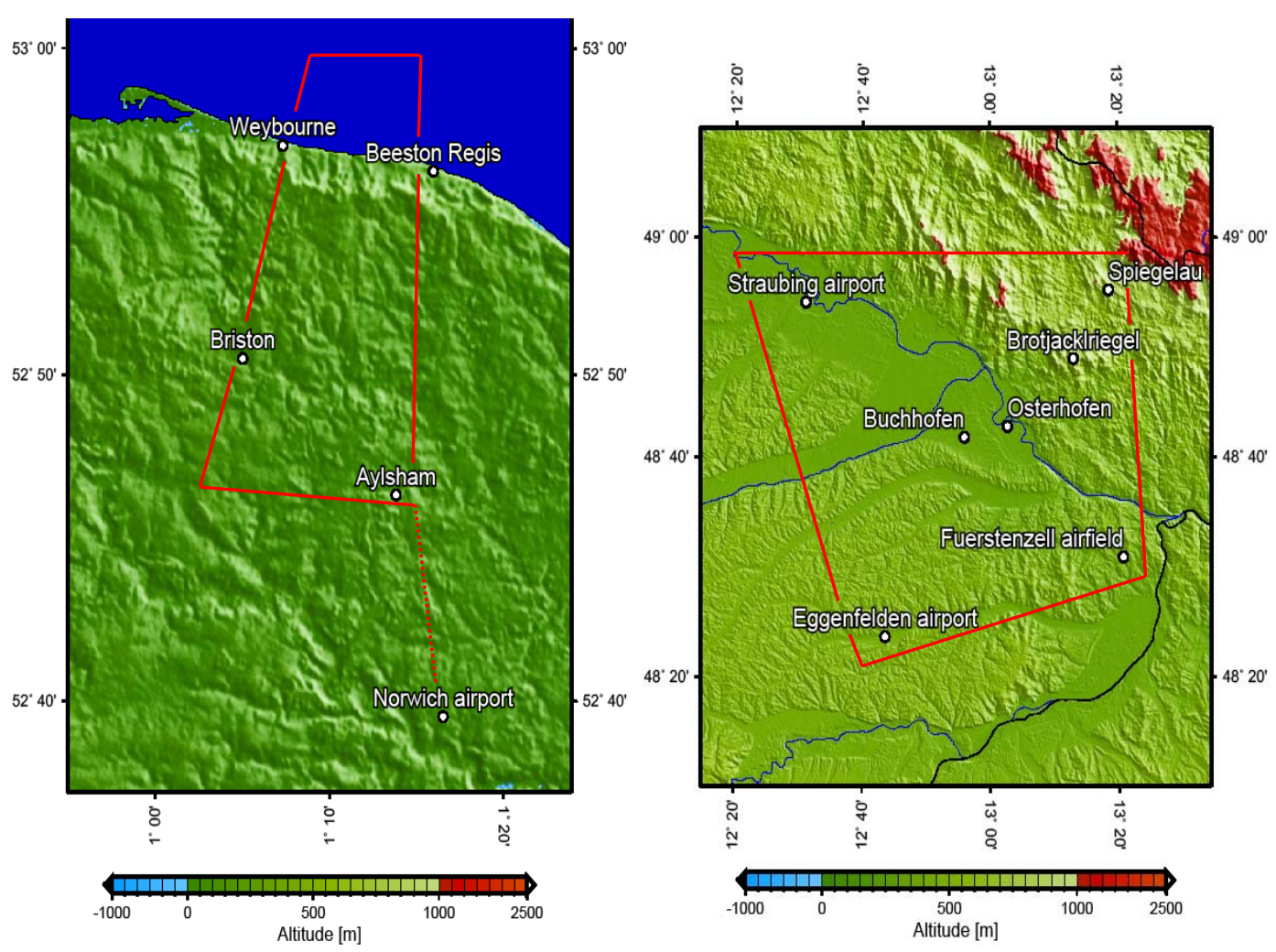

Fig. 1. The topography of both field campaign areas in East Anglia and Bavaria. The measurement grid in East Anglia of about $12 \times 20 \mathrm{~km}^{2}$ lies at the seaside north-east of the aircraft operation basis at Norwich airport. At the second campaign in Bavaria the measurement grid of about $55 \times 55 \mathrm{~km}^{2}$ includes the aircraft operation basis at Straubing airport.

density within and above clouds, microphysical parameters of clouds and aerosol parameters

Additionally an ultralight aircraft (Junkermann, 2005) was used during the first campaign in East Anglia for measuring ozone, aerosol properties and spectral actinic flux density around clouds (small scale variability of the actinic flux density). Further a hot air balloon (Cameron Viva 77) was operated for specific measurements of the effective albedo and actinic flux density vertical profiles in East Anglia (Webb et al., 2004). Each aircraft also contributed to cloud geometry data e.g. altitude of cloud base and cloud top. In addition each aircraft logged basic data such as position, altitude, speed and direction during flight.

\section{Partenavia PL:}

On board of the Partenavia P68B aircraft, operated by the Leibniz-Institute for Tropospheric Research (IFT), radiation, microphysical and standard meteorological measurements were performed. Up- and downwelling irradiances were measured by the Albedometer (Wendisch et al., 2001; Wendisch and Mayer, 2003) in the wavelength range between 350 and $1000 \mathrm{~nm}$. Up- and downwelling actinic flux density data were collected in a wavelength range between
$280 \mathrm{~nm}$ and $700 \mathrm{~nm}$ by the actinic flux density meter (AFDM; DFD/DFU) described by Jäkel et al. (2005). The optical inlets of the Albedometer and the AFDM mounted at the top and the bottom of the aircraft were actively stabilized in a horizontal position with respect to the Earth-fixed coordinate system during the flight within a range of $\pm 6^{\circ}$ pitch and roll angle. The time resolution of both instruments was less than $1 \mathrm{~s}$. During the second INSPECTRO campaign the Photo Diode Array (PDA) was replaced by a Charge Coupled Device (CCD). This new development of ZEISS (Oberkochen, Germany) enabled a higher sensitivity in the UV-B resulting in an extension of the reliable spectral range between 290 and $650 \mathrm{~nm}$, as well as a higher time resolution. In addition, the sampling time was decreased to $100 \mathrm{~ms}$ which corresponds to $6 \mathrm{~m}$ spatial resolution for an aircraft flight velocity of $60 \mathrm{~m} / \mathrm{s}$ (Jäkel et al., 2007).

All spectrometers have been calibrated in absolute irradiance units $\left(\mathrm{W} \mathrm{m}^{-2} \mathrm{~nm}^{-1}\right)$ using a $1000 \mathrm{~W}$ tungsten halogen Lamp (Manufactured by OMTec GmbH, Teltow, Germany, lamp no. 28), which is traceable to an absolute level (PTB-SL 144) maintained at PTB (PhysikalischTechnische Bundesanstalt, Braunschweig, Germany) with an absolute accuracy of $\pm 3 \%$ in the wavelength range between $400 \mathrm{~nm}$ and $770 \mathrm{~nm}$ and $\pm 5 \%$ in the spectral regions 
below $400 \mathrm{~nm}$ and above $770 \mathrm{~nm}$. The wavelength averaged FWHM values of all the spectrometers were determined: $\mathrm{FWHM}_{\text {Albedometer }}=3.0 \mathrm{~nm}, \mathrm{FWHM}_{\mathrm{AFDM}-\mathrm{PDA}}=2.5$ and $2.6 \mathrm{~nm}$, respectively, $\mathrm{FWHM}_{\mathrm{AFDM}-\mathrm{CCD}}=1.5 \mathrm{~nm}$. An overall uncertainty for the spectral irradiance measurements with the Albedometer of $\pm 4 \%$ for wavelengths $\lambda=400$ $700 \mathrm{~nm}$ and of $\pm 6 \%$ for $\lambda<400 \mathrm{~nm}$ and $\lambda>770 \mathrm{~nm}$ was estimated (Wendisch and Mayer, 2003). An overall uncertainty of $\pm 8 \%$ in the UV range and $\pm 5 \%$ in the visible spectral range were given for the AFDM by Jäkel et al. (2005).

Aerosol particle size distributions for particle diameters between 0.1 and $1 \mu \mathrm{m}$ were sampled with a commercial Passive Cavity Aerosol Spectrometer Probe (PCASP-X, manufactured by Particle Measuring Systems, Inc., Boulder, CO, USA). From these distributions the effective particle radius and particle number concentration were derived. Details of the calibration and data processing can be found in Keil et al. (2001). A Particle Volume Monitor (PVM) was used to measure the liquid water content (LWC) for droplets with diameters below $30 \mu \mathrm{m}$ and with a measurement uncertainty of about $10 \%$. The droplet size distribution measurements were performed for droplet diameters below $40 \mu \mathrm{m}$ with the Fast Forward Scattering Spectrometer Probe (Fast-FSSP). The accuracy of the effective radius derived from the FSSP measurements was within 5\%. In addition a constant temperature hot wire Nevzorov probe manufactured by SkyTech Research Inc. (Toronto, Canada) was used for LWC and total water content (TWC) measurements in the range between $0.003 \mathrm{gm}^{-3}$ and $3 \mathrm{gm}^{-3}$.

\section{Partenavia PG:}

The main task of the Garmisch-Partenavia during the INSPECTRO campaigns was to measure spectral actinic flux density within, between and above the clouds. The corresponding spectroradiometer system (METCON, Glashütten, Germany) is based upon two photo diode array spectrographs (ZEISS, Oberkochen, Germany) with a FWHM of approx. $2.1 \mathrm{~nm}$ and a $0.83 \mathrm{~nm}$ pixel distance in the range of 250 to $700 \mathrm{~nm}$. Both spectrographs were temperature stabilized in one box at $(20 \pm 1)^{\circ} \mathrm{C}$. The entrance slits were connected to the actinic heads using a quartz fibre. Both heads were mounted in a fixed position on top of the aircraft between the wings (PGD, downward flux) and at the bottom of the aircraft (PGU, upward flux), respectively. The time to measure one spectrum was in the range of $3 \mathrm{~s}$. This has led to a horizontal resolution of the radiation measurements of approximately $170 \mathrm{~m}$ assuming a ground speed of approximately $55 \mathrm{~m} / \mathrm{s}$. The spectroradiometer was calibrated in the laboratory with a $1000 \mathrm{~W}$ FEL lamp which was traceable to a secondary standard of the Physikalisch-Technische Bundesanstalt (PTB, Braunschweig, Germany). The installation into the aircraft was possible without dismounting the fibres or other parts of the system. However, the calibration was checked against the other spectroradiometers during the in- tercomparison period of the campaigns. A self constructed broadband instrument measuring downward flux of photolysis frequencies of $\mathrm{NO}_{2}$ was used for reasons of quality control of the spectroradiometer data.

The cloud droplet size distribution was measured with a forward scattering probe (FSSP-100; Knollenberg, Boulder, Colorado) in the size range of $0.5-47 \mu \mathrm{m}$ diameter in 20 size bins. The time resolution of the measurements was approximately $10 \mathrm{~s}$. The calibration of the FSSP is performed several times during the campaign using glass beads of different sizes. Up to 100 glass beads of well defined sizes were passed through the FSSP by a vacuum cleaner mounted at the rear of the FSSP. The airborne measurement of the backscattering coefficient of the aerosols was performed with a nephelometer (TSI inc., St. Paul, MN, USA) measuring at the three wavelengths $(450 \pm 40) \mathrm{nm},(550 \pm 40) \mathrm{nm}$ and $(700 \pm 40) \mathrm{nm}$. The time resolution was $6 \mathrm{~s}$.

\section{Cessna (C):}

On board the Cessna 182 light aircraft an Optronic 742 wavelength-scanning spectroradiometer (GBR) was installed. The spectroradiometer was mounted in a temperature stabilised box. The instrument deployment has been described by Webb et al. (2000). A bifurcated fibre is used to sample the irradiance from upward and downward pointing cosine response input optics. The signal from up and down pointing fibres was alternated at the entrance slit to the double monochromator so that the sampling sequence during a scan was alternated between up and down at a certain wavelength. The monochromator has a spectral slit function with a FWHM of $1.5 \mathrm{~nm}$. The Optronic 742 was calibrated using a $200 \mathrm{~W}$ transfer standard traceable to the National Institute for Standards and Technology (NIST). The $200 \mathrm{~W}$ lamps were used during the campaigns to check the absolute calibration and allow for correction before the data were submitted. The wavelength alignment of the monochromator was also frequently checked using a mercury lamp and was within $0.1 \mathrm{~nm}$. During this project the scans were in $10 \mathrm{~nm}$ steps from $300 \mathrm{~nm}$ to $500 \mathrm{~nm}$. The time required for one scan (up and down) was less than 2 min, during which time the aircraft travelled approximately $7 \mathrm{~km}$. The monochromator was set from time to time to a single wavelength and alternated continuously between the upward and downward inputs at the designated wavelength.

Also mounted on the Cessna during the campaign in Straubing was a two-channel Photodiode array spectrometer (GBE/GBS) with a pair of $2 \pi$ actinic heads (METCON inc., Glashütten, Germany). Unlike the cosine head which weights the incoming radiation with the cosine of the angle of incidence, an actinic head provides un-weighted data from the upper hemisphere $(2 \pi)$. The head is attached via two $5 \mathrm{~m}$ long quartz fibres to a pair of solid state single monochromators mounted in a standard $19^{\prime \prime}$ rack sized box. The spectrometer scans both channels from 290 to $700 \mathrm{~nm}$ 
simultaneously with both heads having slit functions with a FWHM of $(2.2 \pm 0.1) \mathrm{nm}$. The two $2 \pi$ sensor heads were mounted with one facing upwards (GBS) and the other downwards (GBE) on the aircraft to measure the total $4 \pi$ actinic flux density. To prevent an overlap of the fields of view, shadow bands were fitted to both heads. The spectrometer was operated in simultaneous mode during the flights producing 3 pairs of spectra every $10 \mathrm{~s}$ with three different integration times $(300,600$ and $800 \mathrm{~ms})$. The spectroradiometers were calibrated using a $200 \mathrm{~W}$ transfer standard traceable to NIST. In addition the spectrometer calibration was checked at the beginning and end of the campaign and no significant changes were observed. The wavelength alignment was measured during the absolute calibration checks.

\subsection{Ground based instrumentation}

The ground-based instrumentation mainly consisted of spectroradiometer systems for the measurement of spectrally resolved actinic flux density and irradiance. From the technical point of view the spectroradiometers can be divided into two groups: scanning systems and diode array systems. The advantage of the diode array systems beside robustness and low costs is a time resolution within a few seconds per spectrum (e.g. 290-600 nm) compared to scan times of approximately $6 \mathrm{~min}$ for the scanning systems. Especially during periods of rapidly changing weather conditions and particularly for airborne measurements this advantage is very important.

Additionally meteorological parameters like cloud type and cloud cover have been obtained from sky images as well as aerosol properties in the cloud free regimes by lidar measurements. During the first campaign direct measurement of free radicals and other chemical parameters at the surface were performed to allow a comparison of measured and calculated radical concentrations.

For reasons of quality control of the measured spectral actinic flux density data spectral irradiance was measured at each site simultaneously to detect short term changes of the actinic flux density instrument. Additionally a quality control measure was provided by mobile reference systems travelling from site to site to check the long-term stability of the spectroradiometer systems.

\subsubsection{Spectroradiometer systems}

This section provides a detailed description of all spectroradiometer systems deployed for ground based measurements during the campaigns and introduces the abbreviations used further on in the paper.

ATI: The DTM 300 of Bentham (Bentham inc., Reading, UK) consists of a double monochromator with $300 \mathrm{~mm}$ focal length and two sets of holographic gratings with 1200 and $2400 \mathrm{rules} / \mathrm{mm}$ respectively. With the $1200 \mathrm{rules} / \mathrm{mm}$ grating the slitwidth (FWHM) is $0.96 \mathrm{~nm}$ and the wavelength uncertainty is less than $0.1 \mathrm{~nm}$. The input optics for the measure- ment of global irradiance and actinic flux density were connected to the spectroradiometer via a Y-shaped fibre. Moreover both input optics were equipped with a shutter that opens and closes the entrance of the fibre inside the heads. With this setup it was possible to measure global irradiance and actinic flux density at each wavelength step within seconds, so the measurements were almost simultaneous. This minimizes differences in both radiation quantities that are due to changing conditions. Global irradiance was detected with a specially shaped teflon diffuser to minimize the cosine error (http://www.photobiology.com/UVR98/schreder/ index.htm). The usual wavelength range of the measurements was between 280 and $600 \mathrm{~nm}$. The signal was detected with a photomultiplier operated at $600 \mathrm{~V}$, which gives a lower limit for irradiance of about $10^{-6} \mathrm{~W} \mathrm{~m}^{-2} \mathrm{~nm}^{-1}$. The absolute calibration of the spectroradiometer was based on a $1000 \mathrm{~W}$ halogen lamp, traceable to the Physikalisch Technische Bundesanstalt (PTB, Braunschweig, Germany). The Bentham instrument also measured the direct irradiance with a custom optic with a field of view about $1.5^{\circ}$. For an absolute calibration of the direct spectral irradiance a $1000 \mathrm{~W}$ calibrated lamp source was positioned at a distance of about $3 \mathrm{~m}$. To obtain the irradiance of the lamp at this distance, the irradiances from the calibration certificate were scaled by the inverse square law. During the first campaign the spectroradiometer system was placed at Weybourne and at Buchhofen during the Bavarian campaign.

GRT: The Brewer spectroradiometer was operated by the University of Thessaloniki (LAP-AUTH) at Spiegelau (Bavaria), respectively. The heart of the system is a double monochromator consisting of two identical spectrometers equipped with holographic diffraction gratings (3600 lines $/ \mathrm{mm}$ ) operating in the first order. The operational spectral range of the instrument for the global irradiance measurements is $287.5-366 \mathrm{~nm}$, and its spectral resolution was $0.55 \mathrm{~nm}$ at full width at half maximum (FWHM). Details on the operation, the calibration for the global irradiance and total column ozone measurements are given in Bais et al. (1996).

$D E G$ : This spectroradiometer system bases on a double monochromator DTM300 from Bentham instruments (Bentham inc., Reading, UK ) with a focal length of $300 \mathrm{~mm}$, a turret for the use of up to three gratings ( 2400 lines $/ \mathrm{mm}$, 1200 lines $/ \mathrm{mm}$ and 600 lines/mm) as well as two exit slits after the second monochromator. The use of a photomultiplier, type 9205QB from EMI and a Si-photodiode in combination with the choice of the different gratings enables coverage of the spectral range between 200 and $1100 \mathrm{~nm}$ for the measurements. The measured full width at half maximum (FWHM) of the slit function was $0.96 \mathrm{~nm}$. The entrance optics for the measurement of global irradiance consisted of a self constructed head in combination with a commercially available diffuser (Bernhard and Seckmeyer, 1997). In order to measure the spectral actinic flux density a $2 \pi$ actinic head manufactured by METCON was used (METCON inc., 
Glashütten, Germany). Both of the former entrance optics were coupled to the 2Way-SAM (switching mirror; Bentham, Reading, UK) to allow rapid switching between both values. Each entrance optic was coupled by a quartz fiber to the monochromator. The third entrance of the monochromator was used for the measurement of direct irradiance in combination with a self constructed entrance optic and a 2AP solar tracker (Kipp\&Zonen, Delft, Netherlands) to follow the sun. The spectroradiometer system was temperature stabilized at $(20 \pm 0.5)^{\circ} \mathrm{C}$. The calibration was performed with a $100 \mathrm{~W}$ working standard within a lamp house specially designed for field calibrations. The working standard was calibrated with a collective standard based on three calibrated 1000 W FEL lamps provided by the German Physikalisch Technische Bundesanstalt (PTB, Braunschweig, Germany). The expanded uncertainty (comp. to the $2 \sigma$ level) for measurements of global spectral irradiance varies between $6.3 \%$ in the UVA and $12.7 \%$ at $300 \mathrm{~nm}$ and $60^{\circ}$ solar zenith angle (Bernhard and Seckmeyer, 1999). The spectroradiometer system was set up at Briston during the first campaign and during the second campaign at Fürstenzell.

GBM: The Manchester Bentham DTM300 (Bentham inc., Reading, UK) was used during both INSPECTRO campaigns at Beeston Regis (UK) and at Straubing airport (Germany). The double monochromator was fitted with two input optics via fibre optic light guides: a METCON $2 \pi$ actinic head (METCON inc., Glashütten, Germany) and a Schreder J1002 global head (CMS, Kirchbichl, Austria). Each head could be chosen under software control to perform an actinic flux density or global irradiance measurement. The instrument was mounted in a temperature stabilised box kept at a constant $(25.0 \pm 0.3)^{\circ} \mathrm{C}$. For the campaigns the Manchester instrument was calibrated from 290 to $500 \mathrm{~nm}$ at $0.5 \mathrm{~nm}$ steps for both heads. The FWHM of the slit functions for the actinic and the global head were both $0.7 \mathrm{~nm}$. The calibration of the Bentham was performed in the laboratory in Manchester using a $1000 \mathrm{~W}$ traceable to the National Institute of Standards and Technology (NIST, Gaithersburg, MD, USA). Then a $200 \mathrm{~W}$ lamp was used as a transfer standard. This was measured after instrument set-up to check calibration at the start, then every two days until the end of campaigns. Changes in the calibration of more than $3 \%$ were post corrected and the calibration file corrected for the next day measurements. After the first few days the instrument was always found to be stable. A mercury lamp was used to check initial wavelength alignment, which needed no further adjustment during the campaigns.

NTN: This spectroradiometer system used by the NTNU (Norwegian University of Science and Technology) group measured the global and the direct irradiance at Aylsham, East Anglia, and at Eggenfelden, Bavaria. The system consists of a Bentham DM 150 double monochromator (Bentham inc., Reading, UK) and two optical fibres of $4.0 \mathrm{~m}$, one measuring direct irradiance and the other global irradiance. During the INSPECTRO campaigns only global irradinace data were used. The optical input used for global irradiance was provided by CMS-Schreder (Diffuser UV-J1002) with a teflon diffuser and cosine error less than $3 \%$ for incidence angles between $0^{\circ}$ an $70^{\circ}$. The optical head is installed in a heater system. Calibration of the spectroradiometer was performed with a $1000 \mathrm{~W}$ FEL standard lamp (Optronic Laboratories Inc., Orlando, FL, USA). Wavelength calibration was performed using two strong lines from a mercury lamp. The spectroradiometer slit function was measured with a He$\mathrm{Cd}$ laser $(325 \mathrm{~nm})$, and applied in the data analyses. The wavelength accuracies of the solar spectra were checked with respect to Fraunhofer lines using the software SHICrivm (Slaper et al. 1995). The global irradiance measurements were performed from $290 \mathrm{~nm}$ to $500 \mathrm{~nm}$ in steps of $0.5 \mathrm{~nm}$. The second quartz fibre connected to the monochromator was equipped with a direct sun optic from Bentham consisting of a $20 \mathrm{~cm}$ tube with a diameter of $4 \mathrm{~cm}$ and baffles every $5 \mathrm{~cm}$. The entrance optic was mounted to the quartz fibre and is attached to a tracking system with two microstepping motors for azimuth and zenith direction.

$D E D / D E M$ : Each spectrometer was based on a single monochromator with no moving parts (ZEISS, Oberkochen, Germany). Made from ceramics/glass, the monochromator had negligible sensitivity to temperature changes. This resulted in very stable wavelength settings. The spectrometer also had an extremely fast response time. It used a 512 pixel diode array detector with a spatial resolution of ca $0.85 \mathrm{~nm}$ (pixel-distance) and an FWHM of ca. $2.1 \mathrm{~nm}$. The spectrometer system allowed to determine ozone photolysis rates within $2 \mathrm{~s}$, depending on the solar elevation. A $1000 \mathrm{~W}$ FELlamp, which is traceable to the Physikalisch Technische Bundesanstalt (PTB) was used for the calibration.

RJB: The RJB spectroradiometer system was described in detail by Hofzumahaus et al. (1999). During the second INSPECTRO campaign the system was used at Spiegelau to measure the spectral actinic flux density. The main components are an actinic flux density quartz receptor optic, a $10 \mathrm{~m}$ quartz fiber, a double-monochromator DTM300 of Bentham (Bentham inc., Reading, UK), and a UV sensitive photomultiplier tube connected to a dc amplifier (Bentham 267). Absolute calibration is made with a PTB traceable 1000 W Tungsten Lamp Osram Sylvania (Gigahertz Optik, Puchheim, Germany) prior to and after the campaign. Field calibration was made with four $45 \mathrm{~W}$ secondary standards (Optronics), typically every 3-5 days with at least two lamps at a time. Wavelength positions were checked with a low pressure Hg-lamp using 4-5 lines in the range $295-550 \mathrm{~nm}$. The FWHM was $0.95 \mathrm{~nm}$. With a step size of $0.5 \mathrm{~nm}$, scanning times of about $4 \mathrm{~min}$ resulted for the $290-500 \mathrm{~nm}$ scanning range.

RJD: The RJD system consists of a diode array spectroradiometer (Meteorologie Consult $\mathrm{GmbH}$, Glashütten, Germany) and using a quartz entrance optic to measure the spectral actinic flux density. The collected light is dispersed using a monolithic single monochromator (ZEISS, Oberkochen, 
Germany) and detected by a 512 pixel diode array (Hamamatsu Photonics, Japan). A $280-700 \mathrm{~nm}$ wavelength range is covered at a pixel width of $0.83 \mathrm{~nm}$ and a nominal resolution of $2.1 \mathrm{~nm}$. In a wavelength range below about $315 \mathrm{~nm}$ stray light limits the precision of measurements under atmospheric conditions. During the Bavarian campaign the system was operated on top of the Brotjacklriegel mountain.

QASUME: The QASUME spectroradiometer was used as a mobile reference system for spectral irradiance measurements during the first campaign in UK. The system consists of a commercially available Bentham DM-150 double monochromator with an effective focal length of $2 \times 150 \mathrm{~mm}$ and a 2400 lines $/ \mathrm{mm}$ grating. The wavelength range is 250 to $500 \mathrm{~nm}$ and the entrance and exit slit width was chosen to yield a near triangular slit function with a full width at half maximum resolution of about $0.8 \mathrm{~nm}$. The smallest wavelength increment is $0.0025 \mathrm{~nm}$. The spectroradiometer has two entrance ports which can be selected by a remotely controlled internal mirror. The solar irradiance is sampled through a specially designed entrance optic (Model UV-J1002, CMS-Schreder, Kirchbichl, Austria) which is connected to one port of the spectroradiometer through a quartz fiber. The second entrance port holds a pencil ray Mercury lamp (Model 6035, Oriel, Darmstadt, Germany) which is used to check the wavelength setting of the spectroradiometer. Up to September 2003 a side-window type photomultiplier (PMT) was used as detector, and then it was replaced with an end-window type bi-alkali PMT (Electron tubes 9250QB). The photocurrent is measured with a six decade current amplifier, integrated for a $100 \mathrm{~ms}$ time window, digitised and transferred to a computer for further data treatment and storage. The irradiance scale of the QASUME spectroradiometer is based on a number of $1000 \mathrm{~W}$ FEL type tungsten halogen lamps traceable to the primary radiation standard held at the Physikalisch-Technische Bundesanstalt (PTB) in Braunschweig, Germany. Since the instrument is designed for outdoor solar measurements, the whole spectroradiometer system including the data acquisition electronics are contained in a temperature controlled box which is stabilised to a predetermined temperature with a precision of $0.5 \mathrm{~K}$. A more detailed description of the reference spectroradiometer system and the results of its performance from 2002 to 2004 is given by Gröbner et al. (2005) and Gröbner et al. (2006), respectively.

\subsubsection{Ancillary instruments}

Ancillary measurements were performed to characterize the atmospheric conditions during the campaigns regarding the meteorological conditions, the vertical distribution and the optical depth of the aerosols, air chemical parameters as well as cloud parameters. In addition the spectral measurements were complemented by fast sampling broadband instruments such as pyranometer, Biometer or other photoelectric detectors that measured e.g. the photolysis frequencies of $\mathrm{NO}_{2}$ or
$\mathrm{O}_{3}$. All this information was needed for data analysis and quality assurance.

Radiation (broadband instruments and filterradiometers)

While the spectral information and the accuracy of broadband radiometer systems are limited, their fast time response makes them ideal supplements to the more accurate but mostly slower spectral instruments. Three Pyranometers (CM11 and CM21, Kipp \& Zonen, Delft, Netherlands) were used to measure the total global irradiance on a plane surface in the wavelength range from 0.3 to 3 micrometers. The response time of the instruments was $5 \mathrm{~s}$ while data are recorded as averages of $1 \mathrm{~min}$ intervals. The UVB-1 Pyranometer of Yankee Environmental Systems (YES, Turners Falls, MA, USA) has measured the radiation received by a horizontal surface from the entire hemisphere of the sky from 280 to $320 \mathrm{~nm}$. The instrument produced a 0-4 VDC output signal and was thermally stabilized for long term referencegrade measurements. The UV Biometer (v. 501, Solar Light inc., PA, Philadelphia, USA) was used to measure erythemally weighted irradiance with a time resolution of $1 \mathrm{~min}$.

During the second campaign the multichannel radiometer GUV- 541 from Biospherical Inc. (San Diego, CA, USA) was used as a mobile reference instrument for spectral irradiance measurements (GUV). The filterradiometer has five channels at $305 \mathrm{~nm}$ ( $7 \mathrm{~nm}$ bandwidth), $313 \mathrm{~nm}$ (11 nm bandwidth), $320 \mathrm{~nm}, 340 \mathrm{~nm}$ and $380 \mathrm{~nm}$ (all with $10 \mathrm{~nm}$ bandwidth). The instrument logged the global irradiance every $1 \mathrm{~s}$. The detector was temperature stabilized at $40^{\circ} \mathrm{C}$. The instrument was calibrated against the NTN spectroradiometer system (simultaneous measurement).

Further filter radiometers were used to measure $\mathrm{J}\left(\mathrm{NO}_{2}\right)$ and $\mathrm{J}\left(\mathrm{O}^{1} \mathrm{D}\right)$ directly. The radiometers were manufactured by METCON (METCON inc., Glashütten, Germany) and utilize similar entrance optics as the scanning spectroradiometer RJB. The filter instruments measured integrated spectral actinic flux density in a selected wavelength range. The relative spectral sensitivity was selected to reproduce the wavelength dependencies of the products of absorption cross sections and quantum yields of the photolysis processes. The devices thus produced signals proportional to the photolysis frequencies. Laboratory characterisations and field or laboratory calibrations allow a calculation of photolysis frequencies. More details on the technique can be found elsewhere (Junkermann et al., 1989; Volz-Thomas et al., 1996; Bohn et al., 2004). Filterradiometer signals were recorded every $5 \mathrm{~s}$ providing high resolution complementary information on rapid changes of external conditions.

Aerosols and clouds

A mobile lidar VELIS (VEhicle-mounted LIdar System) and two LD-40 lidar-ceilometer (VAISALA, Vantaa, Finland) were employed to provide range and time-resolved 
information on aerosol and cloud properties during the INSPECTRO campaigns. During the first campaign in East Anglia only VELIS was used. The instrument was located at the core site of Weybourne. In 2004 the VELIS was installed at the core site of Buchhofen. The VAISALA LD-40 lidarceilometers were installed at the mountain site of Spiegelau, and at Fürstenzell.

The VELIS lidar was developed at ISAC to retrieve calibrated profiles of aerosol backscatter and extinction coefficients, plus depolarization ratio, at $532 \mathrm{~nm}$ between $200 \mathrm{~m}$ and $20 \mathrm{~km}$ above ground level (a.g.l.). Each VELIS profile was obtained after averaging the returns of 6000 laser shots, corresponding to $6.6 \mathrm{~min}$. Calibrations were performed against climatological molecular density profiles from radiosounding records of nearby airports. One profile every $15 \mathrm{~min}$ was retrieved during the campaign flights. A thorough description of the VELIS inversion procedure and errors of the retrieved backscatter and extinction coefficients can be found in Gobbi et al. (2003). A series of aerosol models (Barnaba and Gobbi, 2001 and 2004) has been implemented to invert the lidar signal and retrieve aerosol properties as extinction coefficient, surface area and volume. Other parameters retrieved by the lidar analysis are the backscatter ratio and the linear depolarization ratio. The backscatter ratio relates the amount of aerosol/cloud backscatter to the molecular one. The depolarization ratio was used to discriminate non-spherical (i.e. solid) particles as dust or cirrus clouds (typical depolarization $\sim 40-60 \%$ ) from spherical ones as liquid aerosols or cloud droplets (typical depolarization of $\sim 1-$ 5\%) (Gobbi et al., 2003). Information on planetary boundary layer (PBL) height plus cloud base and top heights was also retrieved from the VELIS observations by visual analysis of single profiles. In particular, the PBL height was determined as the level of the first change in slope (minimum in signal derivative) of the backscatter signal (Menut et al., 1999). Cloud bottom is defined at the level of sharp increase in backscatter, while cloud top is inferred looking at the uppermost level of increased backscatter in regions of reduced cloud optical thickness (usually near cloud gaps). In fact, determining cloud height in optically thick, unbroken clouds is not possible for this system.

The LD-40 ceilometer was developed by VAISALA to retrieve cloud layers height up to $13 \mathrm{~km}$. This system operated at $855 \mathrm{~nm}$. Cloud base and top, as well as PBL altitude were retrieved with an approach similar to the one described for the VELIS lidar. A code for the analysis of the LD40 record implemented at ISAC, provides contour plots of range-corrected signal and the PBL height. Conversely, tropospheric aerosol profiling is not possible with this instrument due to its much lower signal to noise ratio with respect to VELIS. Eggenfelden and Straubing have regular airfields and thus have their own standard deployment of ceilometers. Therefore, with the exception of Brotjacklriegel, each site was equipped with a ceilometer or a lidar system measuring the cloud base altitude.
Several MICROTOPS II sunphotometers (Solar Light inc., Philadelphia, PA, USA) were used to measure aerosol optical depth (AOD) at 440, 500, 670 and $1020 \mathrm{~nm}$ as well as precipitable water column and total ozone column, depending on the type of instrument.

Cloud cover and cloud type were determined from the analysis of sky camera pictures and eye observations. In addition eye observations of cloud cover in octas, cloud type and cloud altitude in $\mathrm{m}$ were made routinely every hour at the German Weather Service (DWD) stations Fürstenzell and Straubing. In addition eye observation was performed at the core sites of each campaign (Weybourne and Buchhofen).

Meteorological and chemical parameters

During the first campaign ground-based measurements of chemical parameters were made at Weybourne alongside the measurement of standard meteorological data. These included measurements of peroxy radicals $\left(\mathrm{HO}_{2}\right.$ and $\left.\mathrm{RO}_{2}\right)$, ozone, carbon monoxide, nitrogen oxides and peroxides. An overview of the instruments and methods is given in Penkett et al. (1999) and Green et al. (2006). Observations of wind direction and speed as well as temperature obtained from the ground based systems were used for interpretation of the trace gas measurements and in combination with pyranometer data for deriving cloud geometrical parameters like cloud base size, whilst the other chemical data was used to constrain chemical box model calculations which will be described elsewhere in a forthcoming paper (Claire Reeves, personal communication). During the second campaign only meteorological parameters (wind, temperature and humidity) were measured at Buchhofen, and also obtained from the German Weather Service (DWD) stations Straubing and Fürstenzell.

\section{Campaigns}

Instrument intercomparison

During the first week of the first campaign (Norfolk, UK) all the spectroradiometers used at the ground stations, plus the University of Manchester (UMIST) aircraft instrument, were located at the Weybourne site for an instrument intercomparison. This intercomparison lasted 5 days, 4 to 8 September (day numbers 247-251 of the year), during which a range of sky conditions were encountered, including some clear skies. The weather was predominantly dry but cloud cover could change rapidly in the often windy conditions. To minimize the influence of changing conditions all scans were synchronized, with the instruments scanning $290-500 \mathrm{~nm}$ in $0.5 \mathrm{~nm}$ steps with $3 \mathrm{~s}$ per step. Several of the instruments could measure two or more radiation parameters by changing input optics, thus measurements on the full hour were global irradiance, and those on the half hour were actinic flux density. Generally the intercomparison started at 07:00 UTC and 
continued until 18:00 UTC each day. Only the first day began with a few blind scans (each instrument independent of any knowledge of the others). After the first day direct beam scans were added to the schedule if the sun was not occluded by clouds for sufficient time to enable the measurement.

There was also one day of intercomparison at the airport (19 September, day 262) when the QASUME instrument was installed at one side of the apron and the aircraft irradiance instruments mounted alongside, either still installed in the aircraft or removed and placed on the apron. This intercomparison was made during high cloud cover and occasional light rain. The airborne radiation instruments were thus cross-referenced to each other, and the ground based instruments through the QASUME instrument.

During the first week of the second campaign in Germany (GER) all the ground-based and airborne spectroradiometers were located on the airfield of Straubing for an instrument intercomparison. The instruments were mounted on the flat surface of concrete surrounded by grassland or on the roofs of the cabins housing the personnel and control computers, or in their respective aircraft. The intercomparison lasted 5 and half days between 6 and 11 May (days 127-132 of the year). During this time period mainly broken cloud and overcast conditions with occasional rain occurred.

\section{Main campaign}

After intercomparison, equilibration and calibration checks of the instruments the measurement program began for the first campaign on 12 September (day 255 in 2002) and on 14 May (day 135 in 2004) for the second campaign, respectively. All ground based measurements were performed between 08:00 to 18:00 local time throughout the campaign. Each instrument was allowed to scan at its own best speed. Since conditions were expected to differ at the various sites there was no advantage to synchronization and it was better to make the measurement as frequently as possible to capture a particular sky condition. Scan speeds ranged from approximately one step per second to one step per $3 \mathrm{~s}$ dependent on instrument. The standard scans were $290-500 \mathrm{~nm}$ at $0.5 \mathrm{~nm}$ steps $(290-550 \mathrm{~nm}$ during the second campaign), though some instruments were limited to shorter wavelengths and others had the ability to extend further into the visible. In order to check the long term stability of all instruments intercomparisons were conducted at each measurement site once the full campaign was in progress. Therefore, two instruments were chosen as traveling standards for quality control, one instrument for actinic flux density (DED, second campaign) and one instrument for irradiance (QASUME, first campaign and GUV, second campaign).

Two Partenavias, a Cessna and during the first campaign an Ultralight formed the main airborne platforms available for simultaneous flights. For each campaign area a basic flight path was defined around the experimental box shown in Fig. 1 for use in synchronized flights. The flight paths covered the location of the ground stations. During the first campaign the single engine aircrafts (Cessna and Ultralight) flew close to the coast from the edge of Weybourne to Beeston rather than going out to sea, truncating the tip of the flight triangle. Not all flights were flown to this pattern, the Ultralight in particular had its own flight missions, and the Partenavias sometimes made almost vertical profiles to measure the spectral actinic flux density as a function of altitude.

\section{Data products and simulations}

Data homogenization

Homogenization procedures are important to ensure that measurements from all instruments are intercomparable, independent of the instrument type or resolution. This mainly results in correction procedures e.g. for an instrumental wavelength shift, a cosine response error or stray-light errors. Differences in the slit-function between the instruments and inaccuracies in wavelength settings (calibration, instrument characteristics) were corrected using the ShicRIVM algorithm (Slaper et al., 1995). A correction of the wavelength shift and deconvolution of the measured spectra to standardized $1 \mathrm{~nm}$ FWHM spectra was performed. The major post correction procedures used for the spectral instruments GBE and GBS were on the $\mathrm{J}\left(\mathrm{O}^{1} \mathrm{D}\right)$ photolysis rates derived from the Cessna airborne actinic flux density data. Due to the lack of sensitivity of the PDA below $305 \mathrm{~nm}$ and additional straylight influence the parametric correction method developed by Jäkel et al. (2005) was used. For similar reasons a correction procedure was applied for the spectral actinic flux density measurements of the instruments DED, DEM and DFD/DFU.

Photolysis frequencies, aerosol optical depth and total ozone column

The photolysis frequency $J$ in s ${ }^{-1}$ of a substance was calculated on the basis of the measured or simulated spectral actinic flux density in photons $\mathrm{m}^{-3} \mathrm{~s}^{-1}$ as described e.g. in Madronich (1987). Our work set the focus on the photolysis of ozone and nitrogen dioxide. The photolysis rates of the corresponding photo-dissociation processes were calculated using the quantum yields from Matsumi et al. (2002) and Troe (2000) as well as the absorption cross sections from Daumont et al. (1992) and Merienne et al. (1995), respectively.

For the direct spectral irradiance and the aerosol optical depth retrieval following the methodology described in Marenco et al. (1997), the absolute calibrated direct irradiance spectral measurements (BREWER instrument) in the range $290-365 \mathrm{~nm}$ and in steps of $0.5 \mathrm{~nm}$ was used. The spectral aerosol optical depth was determined by comparing the measured cloud-free spectral direct irradiance at the surface to the direct irradiance which was calculated from 
the transfer of the high resolution extraterrestrial spectrum ATLAS 3 (VanHoosier, 1996) through the atmosphere using Beer's law and accounting only for molecular absorption (mainly $\mathrm{O}_{3}$ and $\mathrm{SO}_{2}$ ) and Rayleigh scattering. The method that was used to calibrate the direct irradiance spectra for the GRT spectroradiometer is described in Kazadzis et al. (2005). The Rayleigh optical depth was calculated according to Hansen and Travis (1974) or Bodhaine et al. (1999) and the ozone cross sections were taken from Bass and Paur (1985).

\section{Ground albedo and Satellite information}

The airborne instruments measured the spectrally resolved effective albedo at a certain altitude above ground which was defined as the ratio of the irradiance incident at the downward looking entrance optics to the irradiance incident on the upward looking entrance optics. Since there is a layer of atmosphere between the surface and the actual place of aircraft this effective albedo is a combination of the inhomogeneous albedo of the surface and reflection by the intervening atmospheric layer at a certain altitude above ground. In order to derive the spectral ground albedo the measured data were linearly extrapolated to the surface (Webb et al., 2004). This method has proved valid in clean air conditions. Another method uses the radiation transfer model UVSPEC to remove the effect of the atmospheric layer between the surface and the measurement altitude. Details of this method are described by Wendisch et al. (2003).

Space-borne composite pictures (METEOSAT, MODIS) were used to prepare the flight plans and to define the airborne measurement schedule. AVHRR data were used to derive the cloud cover in a spatial resolution of approx. $1 \times 1 \mathrm{~km}$.

Total cloud cover was provided by the European Cloud Climatology (ECC) data base. The cloud products base on NOAA/AVHRR data and were derived by the AVHRR Processing scheme Over cLouds, Land, and Ocean (APOLLO) including a careful quality control (Meerkötter et al., 2004). An important characteristic of the ECC is its high spatial resolution of approximately $1.1 \times 1.1 \mathrm{~km}^{2}$ in latitude and longitude, respectively. This high resolution allowed the direct comparison with surface observations.

In addition to ground based measurements of the total ozone column, particularly under overcast conditions, when groundbased instruments such as the Brewer could not determine the $\mathrm{O} 3$ column from direct irradiance measurements, the data from the EP-TOMS instrument was used (http: //toms.gsfc.nasa.gov/index_v8.html).

\section{1-D radiation transfer model}

The actinic flux density profiles were simulated using the multi-stream discrete ordinates radiative transfer equation solver DISORT2 based on Stamnes et al. (1988) within the li-
bRadtran software package version 1.0 (Mayer and Kylling, 2005). For all simulations a cloudless US standard atmosphere (Anderson et al., 1986) was assumed. Spectral surface albedos were measured from a low-flying aircraft at each campaign site. The ozone layer thicknesses were derived from direct irradiance measurements. The aerosol optical depth is given by $\tau=\beta \times \lambda^{-\alpha}$ where $\beta$ denotes the Ångström turbidity coefficient and $\lambda$ the wavelengths in micrometers. The Ångström exponent $\alpha$ was set to 1.3. A spring/summer aerosol profile (Shettle, 1989) was used containing rural tropospheric aerosol from MODTRAN 3 (Abreu and Anderson, 1996). Only background conditions of stratospheric aerosols were assumed (from MODTRAN 3). Photolysis rates of $\mathrm{O}_{3}$ and $\mathrm{NO}_{2}$ were computed at a fixed temperature of $298 \mathrm{~K}$ using the absorption cross sections described above. The Solar Ultraviolet Spectral Irradiance Monitor (SUSIM) extraterrestrial solar spectrum measured on board the Space Shuttle during the ATLAS 3 mission in November 1994 (Van Hoosier, 1996) was applied. All actinic flux density simulations accounted for the instrumental spectral response functions.

\section{3-D radiation transfer model}

For the 3-D radiative transfer calculations during the project the MYSTIC (Monte Carlo code for the physically correct tracing of photons in cloudy atmospheres) model was used (Mayer, 2000; Mayer and Kylling, 2005). For calculations in the spectral range of interest the following components are required: (1) a description of the background atmosphere including the profiles of pressure, temperature, and ozone concentration (which are basically available from routine observations); (2) three-dimensional cloud data sets and (3), the surface albedo or the Bidirectional Reflectance Distribution Function (BRDF) which was be parameterized via the threeparameter formula of Rahman et al. (1993). Homogenized radiation data sets have been prepared for all campaign days where sufficient aircraft observations were available, in total 6 days for the first campaign in Norwich, UK and 3 days for the second campaign in Straubing, Germany.

The model precision was determined only by the number of photons. As the Monte Carlo method is a statistical technique, the uncertainty (standard deviation) of the result is proportional to the inverse square root of the number of photons traced. Comparisons for one-dimensional geometries using $10^{9}$ photons have shown an agreement between MYSTIC and the one-dimensional DISORT code (Stamnes et al., 1988) of better than $0.01 \%$ (which was less than the MYSTIC statistical uncertainty for this photon number). In the Intercomparison of 3-D radiation codes (I3RC, http://climate.gsfc.nasa.gov/I3RC), a core group of about 6 models including MYSTIC agreed within typically $0.1-1 \%$ for several inhomogeneous cloud cases.

The calculation of irradiances in a Monte Carlo code is straightforward, by counting photons passing through a given area, normalising the sum of photon weights to the number 
of photons incident at the top of the atmosphere, and multiplying with the extraterrestrial irradiance. The calculation of actinic flux density, however, requires weighting each photon with a factor $1 / \cos \theta$ where $\theta$ is the polar angle of the photon passing through the plane. Within the framework of INSPECTRO, Scheirer and Mayer introduced a new method to calculate the actinic flux density, using the fact that the energy absorbed per unit time is simply the product of the actinic flux density and the absorption coefficient (Madronich, 1987; Mayer and Madronich, 2004). Hence, an alternative method to calculate the actinic flux density is to count the absorbed photons in each grid cell and to divide it by the absorption coefficient. The new method was implemented, tested, and found to perform considerably better than the original algorithm.

\section{Generation of a 3-D cloud field}

Clouds vary significantly in space and time. A 3-D retrieval of clouds from aircraft observations is a great challenge. Until now measurements could not provide the complete three-dimensional cloud structure but only point observations along the aircraft path. If the latter is carefully chosen, and if the cloud stays reasonably constant during the flight, the derivation of the cloud field is possible, or at least the derivation of a cloud field with statistical properties identical to those observed along the flight path. During INSPECTRO we were able to follow both methods, (1) to generate a cloud field which reproduces the observations along the flight path and is statistically similar otherwise; and (2) a cloud field which closely resembles the actual geometrical distribution, by combining the aircraft observations with high-resolution satellite remote sensing.

An automated algorithm CLABAUTAIR (Cloud liquid water content and effective radius retrieval by an automated use of aircraft measurements) (Scheirer and Schmidt, 2005) was used to generate a 3-D-cloud field which exhibits the statistical properties of the microphysical aircraft measurements. As input parameters for the algorithm, liquid water content as well as effective droplet radius were used. On the basis of the airborne data the autocorrelation functions were determined along the flight tracks for every layer, defined by the user. The resulting patterns of the autocorrelation functions were used to extrapolate the data from the initial field (aircraft observations) to the whole 3-D-domain. Finally, the resulting field was forced to fit the measured probability density functions, including cloud-free parts to allow broken or even scattered cloud fields (Scheirer and Schmidt, 2005).

In addition to the high-resolution data sets a method to determine low-resolution data based on $1 \mathrm{~km}$ resolution satellite images combined with averaged vertical profiles of cloud microphysics was developed. For this purpose, cloud cover and optical thickness of each satellite pixel was derived from NOAA/AVHRR using the APOLLO algorithm by Kriebel et al. (2003). The optical thickness thus determined was then distributed over the vertical coordinate using the averaged aircraft profile, starting from the lowest cloudy level identified by the aircraft. For each cloud layer the extinction coefficient was determined from the observed liquid water content and effective droplet size and integrated over altitude until the satellite-derived optical thickness is reached. With that procedure, a variable cloud top was constructed. If the vertical extension of the aircraft profile was not sufficient to reproduce the satellite-derived optical thickness, the profiles were extrapolated using the linear fit to the profile. That way, data sets of about $100 \mathrm{~km} \times 100 \mathrm{~km}$ domain size were created, with a horizontal resolution of $1 \mathrm{~km}$.

\section{Meteorological conditions during both campaigns}

As a result of the different geographical location and time of the year, the cloud base altitude, aerosol optical depth and the total ozone column at East Anglia were much lower compared to the corresponding mean values in Bavaria. The total ozone column ranged between 245 and $310 \mathrm{DU}$ at East Anglia and between 330 and 400 DU in Germany. The influence of clouds and the varying actinic flux density on the photochemistry of peroxy radicals is described in Green et al. (2006) and Fleming et al. (2006).

\section{Clouds}

Completely cloudless days did not occur during either campaign. The most suitable clear sky reference days were 12 September for the first campaign and 20 May of the second campaign. On both days cloudless conditions were observed at least during the flying activities with only some cloud in the mountain area during the second campaign which was dominated by convective cloud formation. During the early morning hours the sky was very often cloudless and the formation of cumulus clouds typically started around 09:00 h (UTC) above the mountain area. The horizontal and vertical extension of the clouds increased until early afternoon. On 21 and 22 May thunderstorms occurred and this resulted in very complex cloud conditions with several cloud layers occurring on the following days. Such complex situations were not analyzed in detail with respect to the limited opportunities of the simulations and for safety reasons of the flights. The maximum flight altitude was below the typical altitude of high clouds. Therefore, when high clouds were present no detailed analysis of data during such conditions was made. Nearly ideal conditions with a single cloud layer occurred on September 13th (broken cumulus), 14th (overcast stratus) and 15th (overcast stratocumulus) in 2002 in East Anglia (Fig. 2). During the second campaign such single cloud layers were observed on 19 May (broken cumulus) and 25th (broken cumulus). 

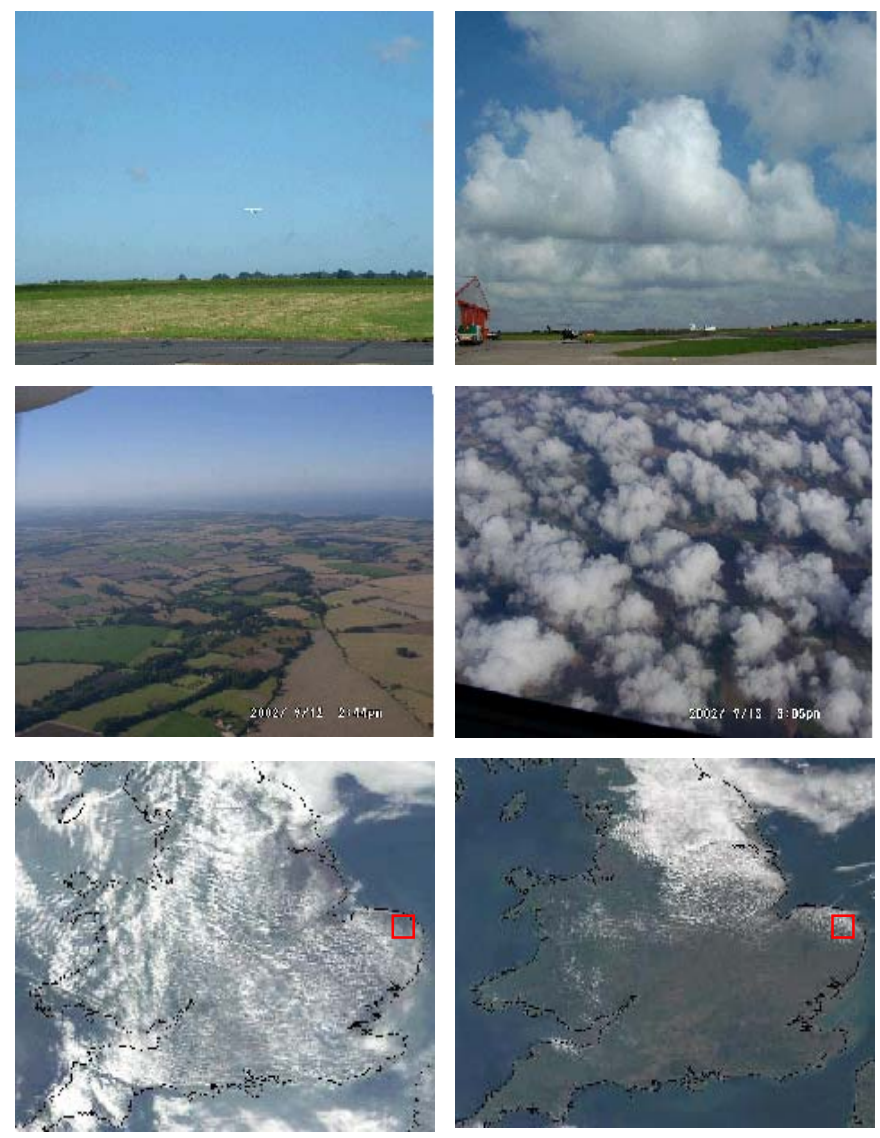
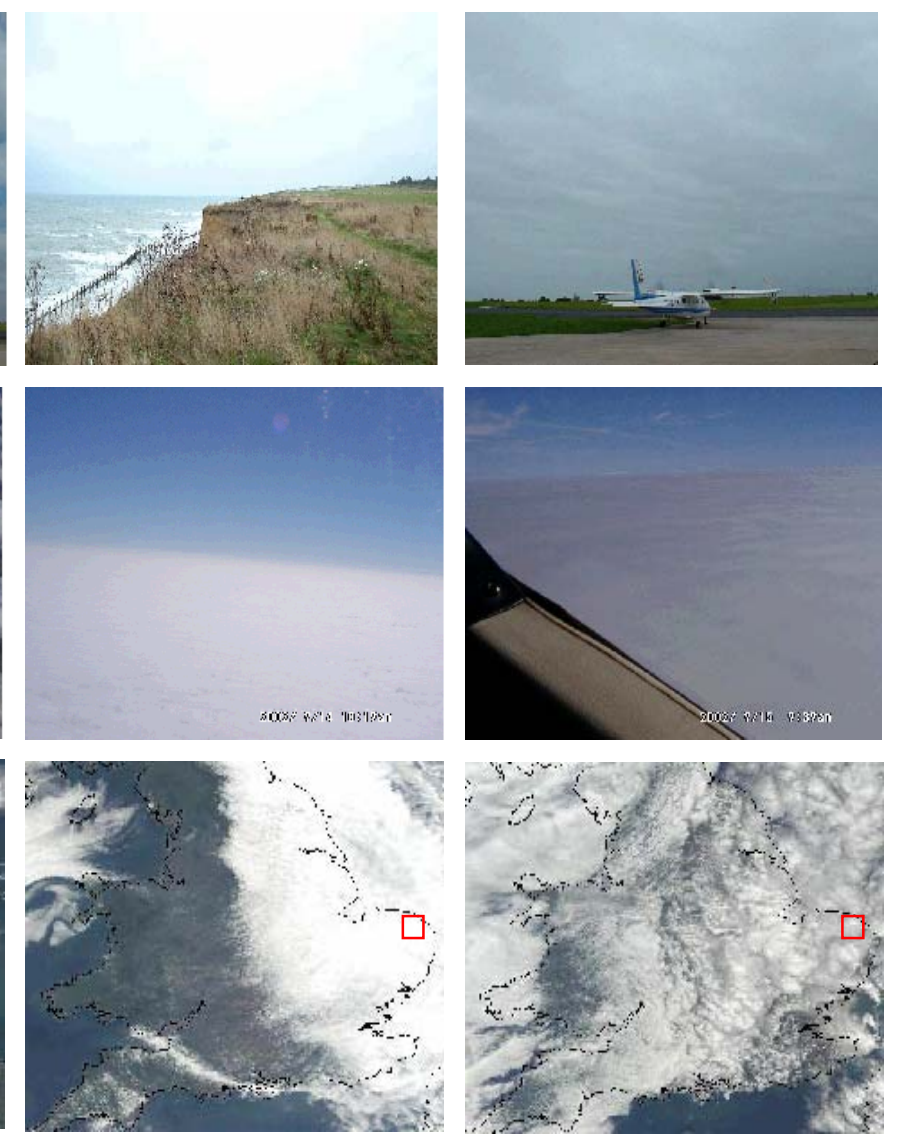

Fig. 2. Sky conditions in East Anglia (from the left to the right) of the 12 September (nearly cloudless), 13th (cumulus hum), 14th (stratus) and 15th (stratocumulus) shown from ground (1st row), from an aircraft (2nd row) and from the MODIS instrument on the TERRA satellite (3rd row). The red square on the 3rd row pictures denotes roughly the campaign area.

\section{Aerosols}

The temperature profile during 12 September with partly cloudless conditions exhibited an inversion at an altitude of approximately $1200 \mathrm{~m}$. Below this inversion the temperature decreased with $0.8 \mathrm{~K}$ per $100 \mathrm{~m}$ altitude. Above the inversion the temperature remained practically constant. During the cloudless day of the second campaign (20 May) the temperature decreased with $0.7 \mathrm{~K}$ per $100 \mathrm{~m}$ up to an altitude of approx. $2000 \mathrm{~m}$ where a small inversion was observed. The aerosol optical depth at $532 \mathrm{~nm}$, the planetary boundary layer (PBL) and the region for cloud generation were much lower during the first campaign at East Anglia compared to the second campaign in Bavaria. This relationship is illustrated in Fig. 3 showing two typical lidar samples measured on the days of 12 September 2002 at East Anglia and on 20 May 2004 in Bavaria. The first change in slope of the descending backscatter ratio profiles of Fig. 3 indicated a PBL height of $400 \mathrm{~m}$ above ground level (a.g.l.) at Weybourne (early afternoon marine PBL) and of $700 \mathrm{~m}$ a.g.l. at Buchhofen (morning continental PBL). Cloud formation regions were revealed by a platform or an increase in backscatter ratio. At Wey- bourne this layer was centred at $800 \mathrm{~m}$ a.g.l., while it is at $1500 \mathrm{~m}$ a.g.l. at Buchhofen (Fig. 3). In addition, the very low depolarization ratio and integral $\mathrm{AOD} \approx 0.12$ observed at Weybourne $(D<2 \%)$ revealed the liquid, unpolluted nature of this likely maritime aerosol. At Buchhofen, increasing depolarization $\mathrm{D} \approx 5 \%$ in the lower PBL indicated the mixing of solid particles with liquid ones. Conversely, liquid particles dominated in the cloud formation region (1300-2300 m above sea level) while some residual dust increased depolarization between 2300 and $5000 \mathrm{~m}$ a.s.1. Both backscatter ratio and integral AOD were much larger than at Weybourne. It is worth noticing the similar contributions from the PBL and the cloud formation region to the AOD.

\section{Ground albedo}

Figure 4 shows the spectral ground albedo derived from spectroradiometer measurements on board the Cessna aircraft (red line, Webb et al., 2004) and on board the Leipzig Partenavia during the first campaign in East Anglia (green line) and the second campaign in Bavaria (black line). The Cessna spectrum was obtained by linear interpolation of the 


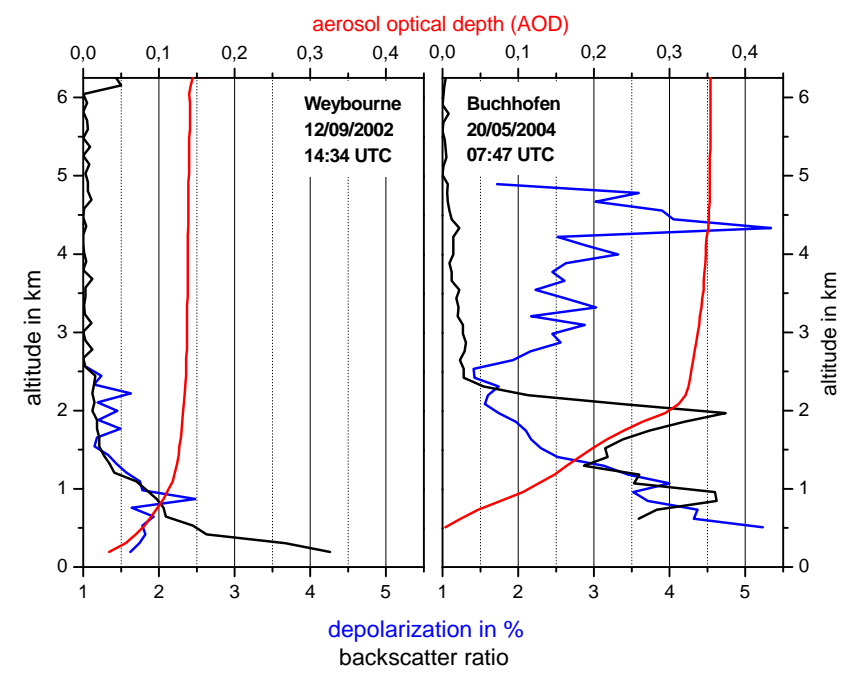

Fig. 3. VELIS lidar profiles retrieved at Weybourne (left plot) and at Buchhofen (right plot). Altitude is plotted with respect to sea level. The black line denotes the backscatter ratio, the blue line indicates the depolarization ratio, and the red line represents the integrated (from ground) aerosol optical depth (AOD) at $532 \mathrm{~nm}$.

measured effective albedo at different altitudes to the surface. The Partenavia spectra were obtained using the radiation transfer model UVSPEC to eliminate the influence of the underlying atmospheric layer. Both albedo spectra agree within the uncertainty limit at wavelengths where they overlap. It can be seen that the spectral albedo of the ground surface generally increases with wavelength through the UV and into the visible. These results are specific to the farmland with some timbered areas.

\section{Spectral actinic flux density measurements}

Instrument intercomparison

The acquisition of a 3-D radiation field requires simultaneous measurements at distinct positions of the investigated grid. An important prerequisite for the interpretation of the measured radiation data set is the knowledge of systematic and statistical deviations between the different measurement systems and the knowledge of the stability of the systems during the campaign. This was achieved by the instrument intercomparison which was performed before the main campaign in combination with a reference system traveling to each instrument (one after the other) during the main campaign periods. At East Anglia the QASUME instrument was used as a mobile reference instrument (traveling standard) for spectral global irradiance measurements and the DED system for spectral actinic flux density measurements. During the second campaign the QASUME traveling instrument was substituted by the GUV instrument measuring spectral irradiance in several narrow band channels.

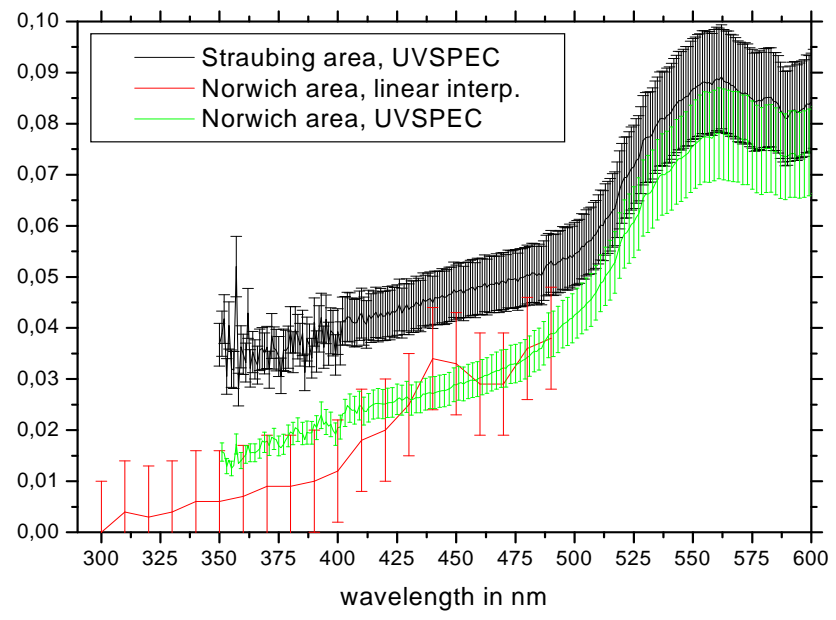

Fig. 4. Spectral ground albedo of both campaign sites. The albedo is derived from airborne spectral irradiance measurements (upward and downward) in combination with a radiation transfer model to eliminate the influence of the underlying atmospheric layer. The error bars denote the uncertainty of the spectral albedo. For the determination of the uncertainty please see Webb et al. (2004) and Wendisch et al. (2005).

In a first step towards the determination of a measurement uncertainty systematic error sources were detected and eliminated during the instrument intercomparison which naturally includes the reference systems. In a second step the long term stability was examined by running the traveling reference system for up to three days at each site over the whole period of the campaign. The resulting ratio of the measurements of each spectroradiometer system to the corresponding reference system should be the same as during the intercomparison period. Hence, the time series of this ratio stands for the stability and a constant ratio indicates a long term stability of the investigated instrument. As an example the time series of the irradiance ratio (spectral irradiance ratio of the reference system to all other systems) versus the day of the year of the first campaign is shown in Fig. 5. With the exception of the GBR instrument and the NTN instrument the ratios remained very stable. The NTN instrument exhibited a ratio of 1.15 at $310 \mathrm{~nm}$. This behavior was detected during the intercomparison (step 1) and based on the use of a wrong calibration file for the NTN instrument. After using the correct calibration the measured spectral irradiance during the days 254 and 255 agree much better with the reference instrument. The GBR instrument has an absolute calibration lower than the other instruments, but it was used for albedo measurements which are an internal ratio, therefore the absolute calibration match to the ground based instruments is less important.

The time series of the spectral actinic flux density ratio of each instrument during the second campaign and the corresponding reference system (DED) is shown in Fig. 6. The 


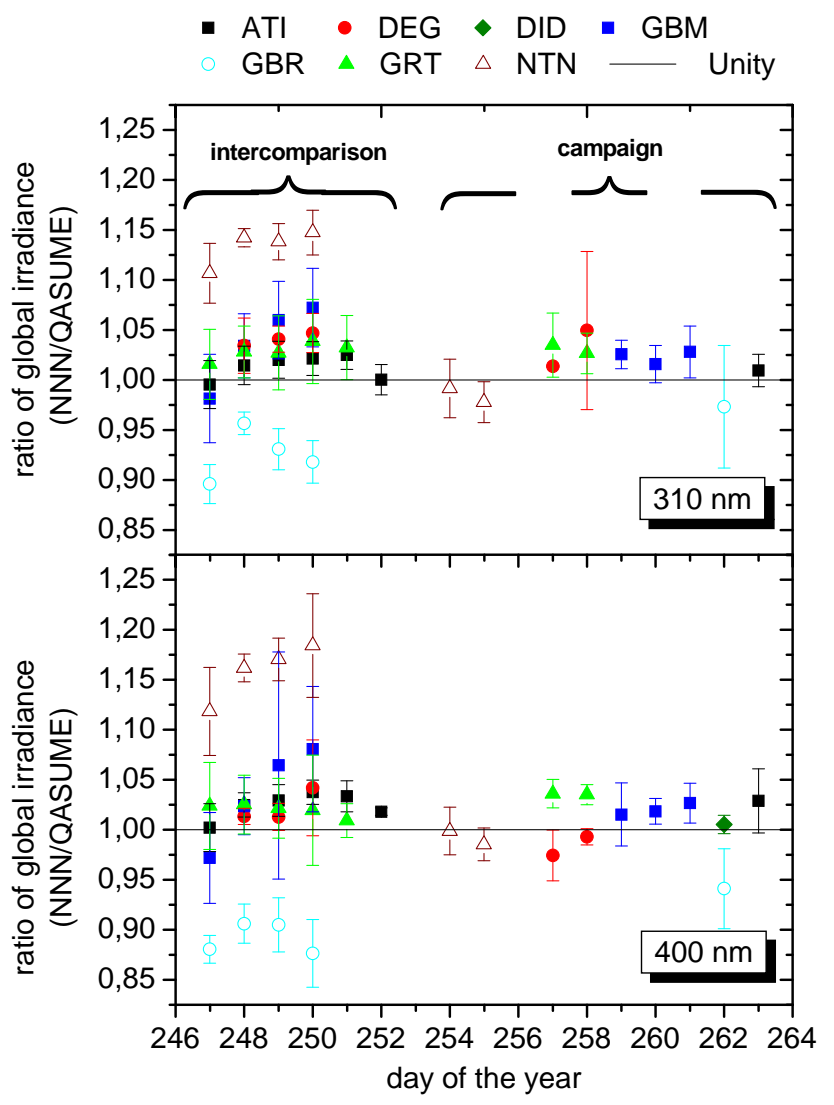

Fig. 5. Check of the long term stability of the spectroradiometer systems used for the ground based measurements of spectral irradiance during the first campaign in East Anglia in 2002. For identifying the ID's of the systems please refer the Sects. 2.2 and 2.3.1. The stability is illustrated as the ratio of the spectral irradiance at $310 \mathrm{~nm}$ (upper plot) and $400 \mathrm{~nm}$ (lower plot) of the reference system (QASUME) to other systems (NNN).

ratios vary around 1.05 for the $\mathrm{J}\left(\mathrm{NO}_{2}\right)$ but remain flat with time. The ratios of the $\mathrm{J}\left(\mathrm{O}^{1} \mathrm{D}\right)$ values were also stable with time but revealed in a first view a systematic deviation of $20-40 \%$ for the instruments PGD, GBS and GBE and a solar zenith angle dependence of nearly all instruments. This fact leads to the conclusion that the solar zenith angle dependence can be attributed to the reference instrument, which operates on the basis of a single monochromator with a diode array detector. Such a single monochromator system overestimates the measurements at shorter wavelengths $(<310 \mathrm{~nm})$ due to stray light contamination (Bais et al., 2003). Therefore, the reference instrument DED used a stray light correction procedure. The disadvantage of the procedure is here an overvaluation of the spectral actinic flux density values for solar zenith angles above 70 degrees. This leads to the day course in the actinic flux density ratio shown in Fig. 6. The DFD instrument corrected the $\mathrm{J}\left(\mathrm{O}^{1} \mathrm{D}\right)$ values instead of the spectral actinic flux density values with respect to solar zenith angle and other atmospheric parameters. The disadvantage of this

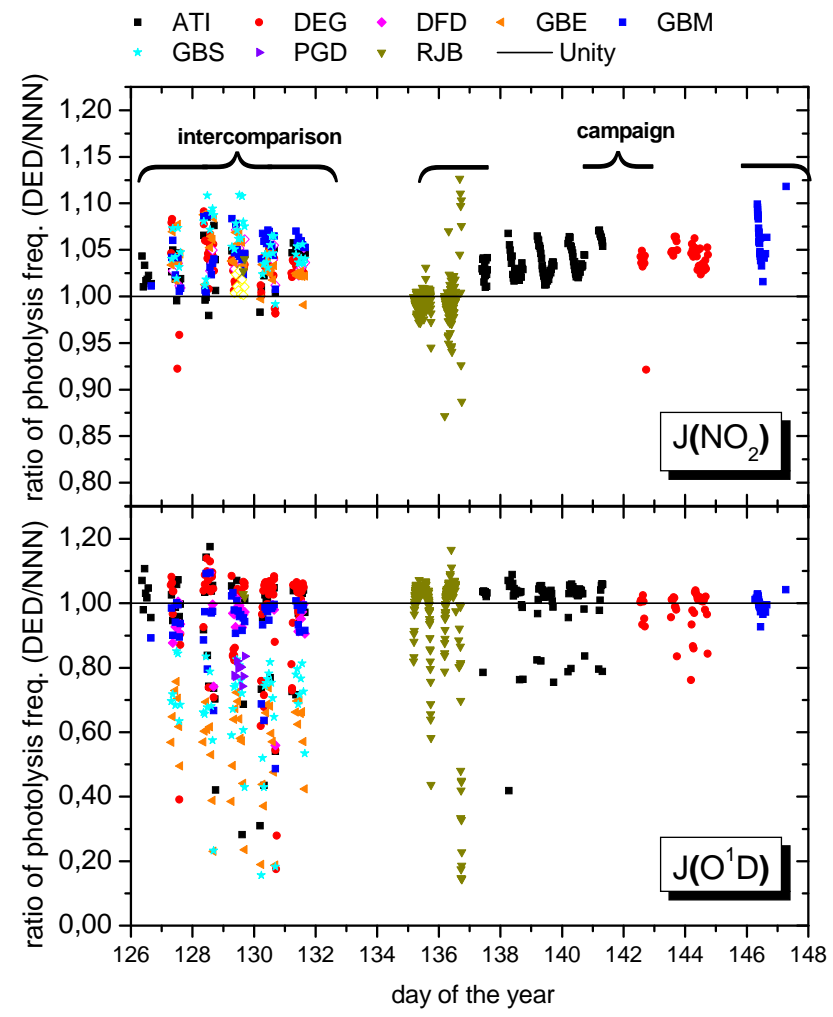

Fig. 6. Check of the long term stability of the spectroradiometer systems used for the ground based measurements of spectral actinic flux density during the second campaign in Bavaria in 2004. For identifying the ID's of the systems please refer the Sects. 2.2 and 2.3.1. The stability is illustrated as the ratio of the photolysis frequency for $\mathrm{NO}_{2}$ (upper plot) and ozone (lower plot) of each system (NNN) to the reference system (DED).

procedure is of course the limitation to $\mathrm{J}\left(\mathrm{O}^{1} \mathrm{D}\right)$ data. In case that no correction procedure was used a systematic deviation up to $40 \%$ of the $\mathrm{J}\left(\mathrm{O}^{1} \mathrm{D}\right)$ value occurs (PGD, GBS, and GBE instruments).

Actinic flux density profiles

During the clear sky conditions of both campaigns the upward and downward spectral actinic flux density were measured on board of three aircraft which allows comparison of the measured profiles of the different aircraft with simulations. The results are shown as photolysis rate profiles for ozone and nitrogen dioxide in Figs. 7 and 8 for the total, downward and upward flux during the clear sky periods of both campaigns (day 255 in 2002 and day 141 in 2004). The measured aerosol optical depth of each day varied between 0.05-0.15 (day 255) and 0.5-0.8 (day 141). This allowed comparison between a "low AOD" case on day 255 and a "high AOD" case on day 141. All photolysis rates of Figs. 7 and 8 were derived from spectral actinic flux density measurements. While the points of each graph denote 


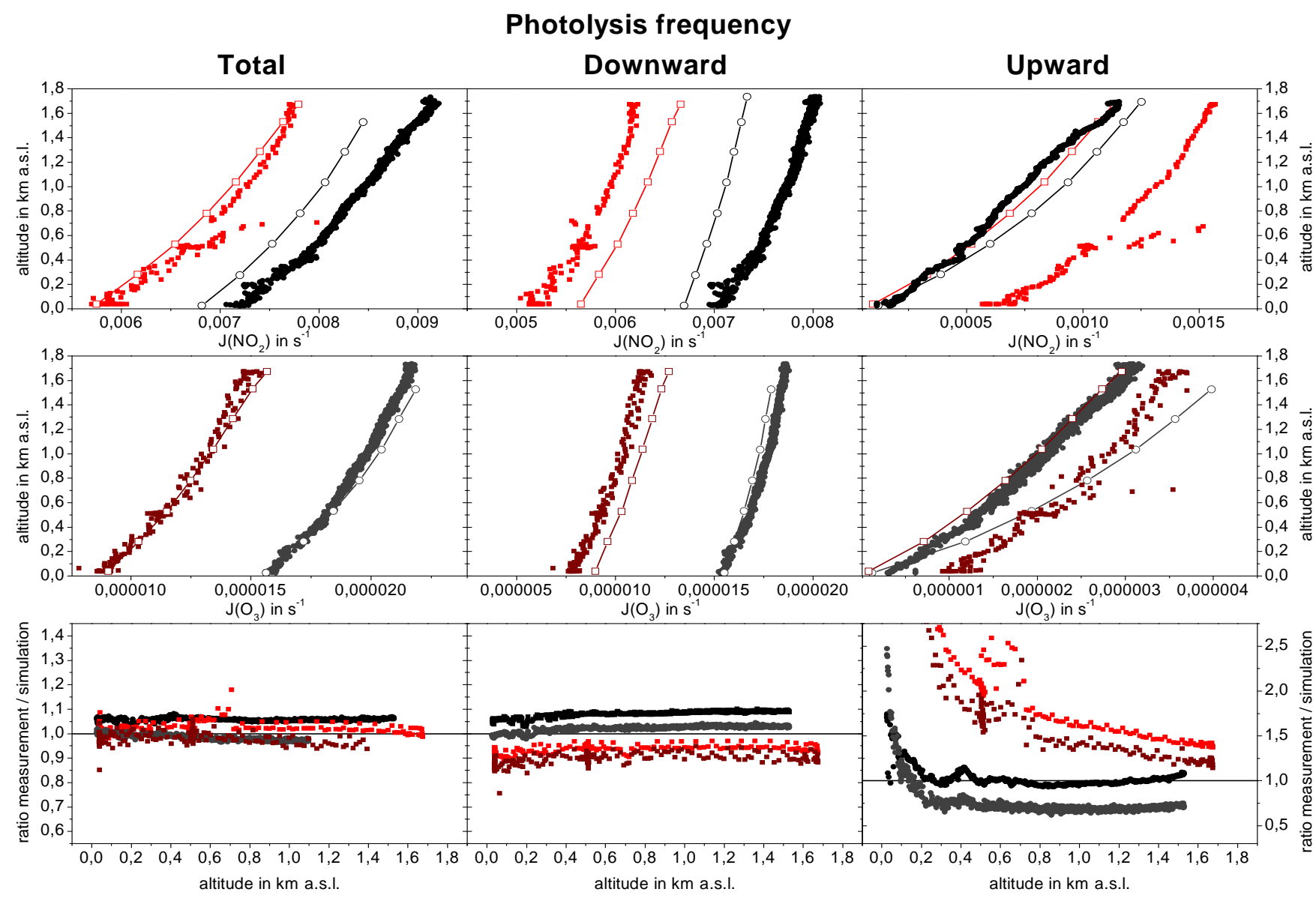

Fig. 7. Comparison of total, downward and upward $\mathrm{J}\left(\mathrm{NO}_{2}\right)$ - and $\mathrm{J}\left(\mathrm{O}^{1} \mathrm{D}\right)$-profiles derived from airborne measurements of two aircraft (PG, PL) and 1-D-radiation transfer calculations along the flight track on 12 September 2002 (day 255). The measured aerosol optical depth of this day lies in the range of $0.05-0.15$ which represents a low aerosol load of the atmosphere. All photolysis rates are derived from the spectral actinic flux density data. While the filled symbols of each graph denote the measurements, the corresponding simulations are represented by open symbols and solid lines. The results of the two aircraft measurements are marked by different colours: red and ruby represent measured or simulated PG data; black and dark grey the PL data and its simulation. The lower three plots represent the corresponding ratios of measured and simulated profiles versus altitude.

the measurements, the corresponding simulations are represented by solid lines at a vertical resolution of $250 \mathrm{~m}$. A horizontal course of the curves in the plots is a result of flying a long period at one altitude and therefore, of a changing zenith angle which in turn changes the photolysis rate. A second effect which produced horizontal spikes is the angle of pitch (roll angle of the lateral axis of the wings) and roll (roll angle of the longitudinal axis) of the aircraft. The second effect occurred particularly for measurements on board of aircraft without a pitch and roll angle stabilization (PG and $\mathrm{C}$ ). The results of the three aircraft were marked by different colours: green and olive represents measured or simulated $\mathrm{C}$ data, red and wine PG data and black and dark grey PL data, respectively. The most noticeable difference between both aerosol cases lies in the shape of the profile which is much more rotund for all three types of fluxes (downward, upward, total) in the case of higher aerosol content. This shape is more pro- nounced for $\mathrm{J}\left(\mathrm{NO}_{2}\right)$ values (red, green and black) than for $\mathrm{J}\left(\mathrm{O}^{1} \mathrm{D}\right)$ values (wine, olive and dark grey).

The ratios of measured and simulated profiles are shown in the lowest row of the plots. The agreement between the measured and simulated downward profiles lies generally in the range of $\pm 15 \%$. The systematically lower $\mathrm{J}\left(\mathrm{O}^{1} \mathrm{D}\right)$ values of the GBS instrument on board of $\mathrm{C}$ seems to be a result from the stray-light correction procedure applied. Before the correction the measured $\mathrm{J}\left(\mathrm{O}^{1} \mathrm{D}\right)$ was approximately $10 \%$ higher than the simulated values. The agreement between measured and simulated upward flux density profiles is much worse. Here the ratio reaches from 0.5 up to factors of 5-10 depending on the aircraft and altitude. In the case of very small ground albedo values the measurement of the upward flux is very sensitive to changes in the pitch and roll angle during the flight. Such changes occur especially at low altitudes after the take off or generally during flight manoeuvres with 

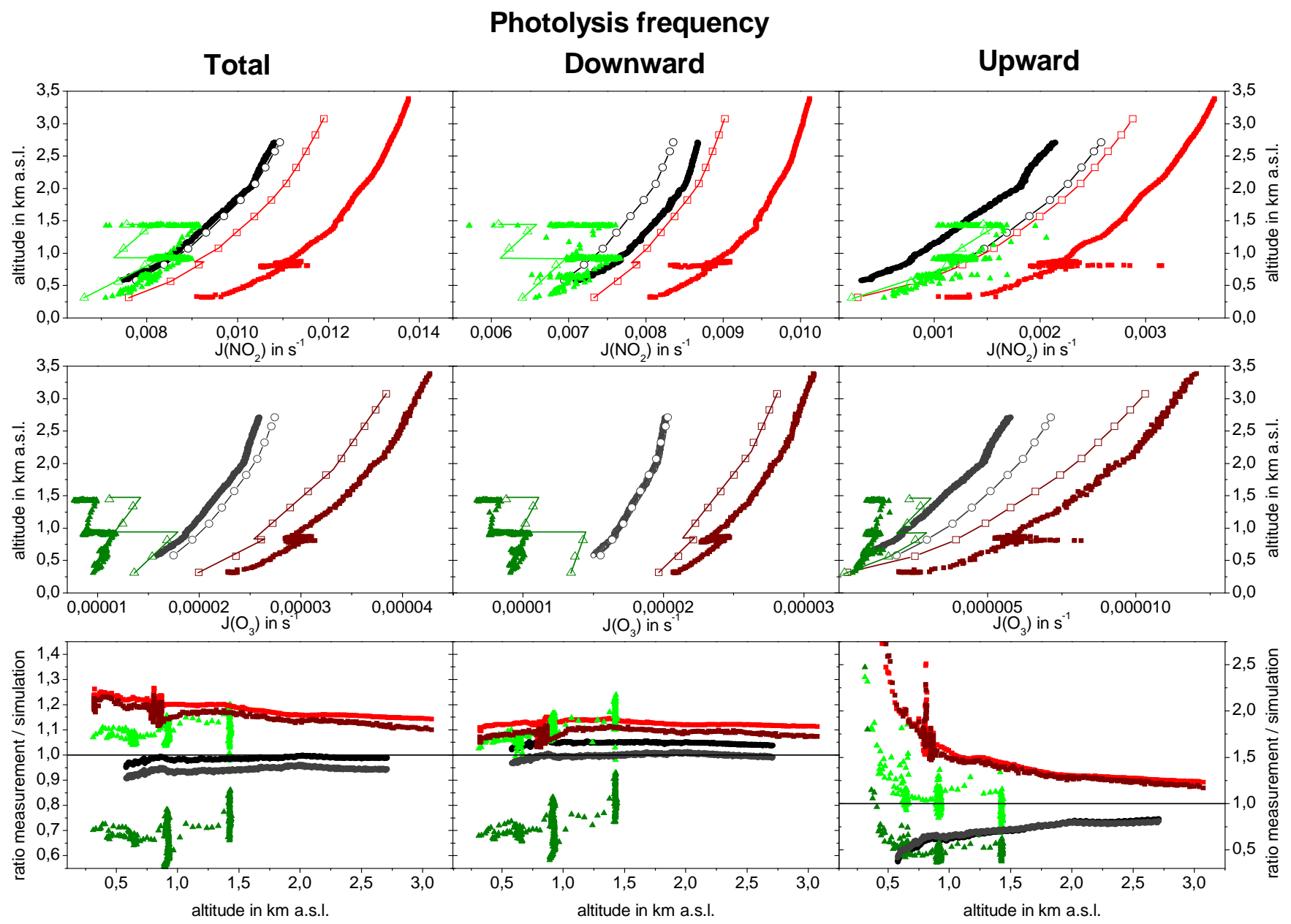

Fig. 8. Comparison of total, downward and upward $\mathrm{J}\left(\mathrm{NO}_{2}\right)$ - and $\mathrm{J}\left(\mathrm{O}^{1} \mathrm{D}\right)$-profiles derived from airborne measurements of three aircraft $(\mathrm{PG}$, PL and C) and 1-D-radiation transfer calculations along the flight trackon 20 May 2004 (day number 141). The measured aerosol optical depth varies between $0.5-0.8$ which represents a "moderate AOD" case. All photolysis rates are derived from spectral actinic flux density data. While the filled symbols of each graph denote the measurements, the corresponding simulations are represented by open symbols and solid lines. The results of the three aircraft are marked by different colours: green and olive represents measured or simulated Cessna data, red and ruby PG data and dark grey and black PL data, respectively. The plots of the lowest line represent the deviation between measured and simulated profiles versus the altitude.

large changes in the altitude over a small area (flying narrow circles). Also, the effective albedo changes the most near the ground. Therefore, a careful interpretation of the upward flux data is needed. The contribution of the upward flux density to the total flux density normally ranges under clear sky conditions between 10 and $25 \%$ depending on the albedo of the underlying atmospheric layer and the ground. The largest deviation of the measured upward flux density from the simulated results occurred if the portion of the upward flux density is small (approx. 10\%). Hence the total flux density exhibited only a small dependency on changing pitch and roll angles during the flight.

The measured profiles of the downward actinic flux density can also be compared with the corresponding ground based measurements instead of the results of radiation trans- fer calculations. This comparison is illustrated in Fig. 9 for the photolysis rates of $\mathrm{NO}_{2}$ (upper plot) and ozone (lower plot). It shows actinic flux density profiles on six selected days and the corresponding mean value of the ground based measurements at the sites of the campaign area (symbols). The error bar represents the variability of the actinic flux density (standard deviation) during the time of measurement of the profile. The extrapolation of each profile towards the ground meets the mean value of the ground based measurements within the uncertainty limits. In addition the variability at the ground (the collective of all sites) reflects the variability of the profile caused by clouds. On the selected "clear sky" day 141 of the second campaign (20 May 2004) the airborne profile (turquoise) was compared with a profile of ground based measurements (turquoise symbols) resulted 

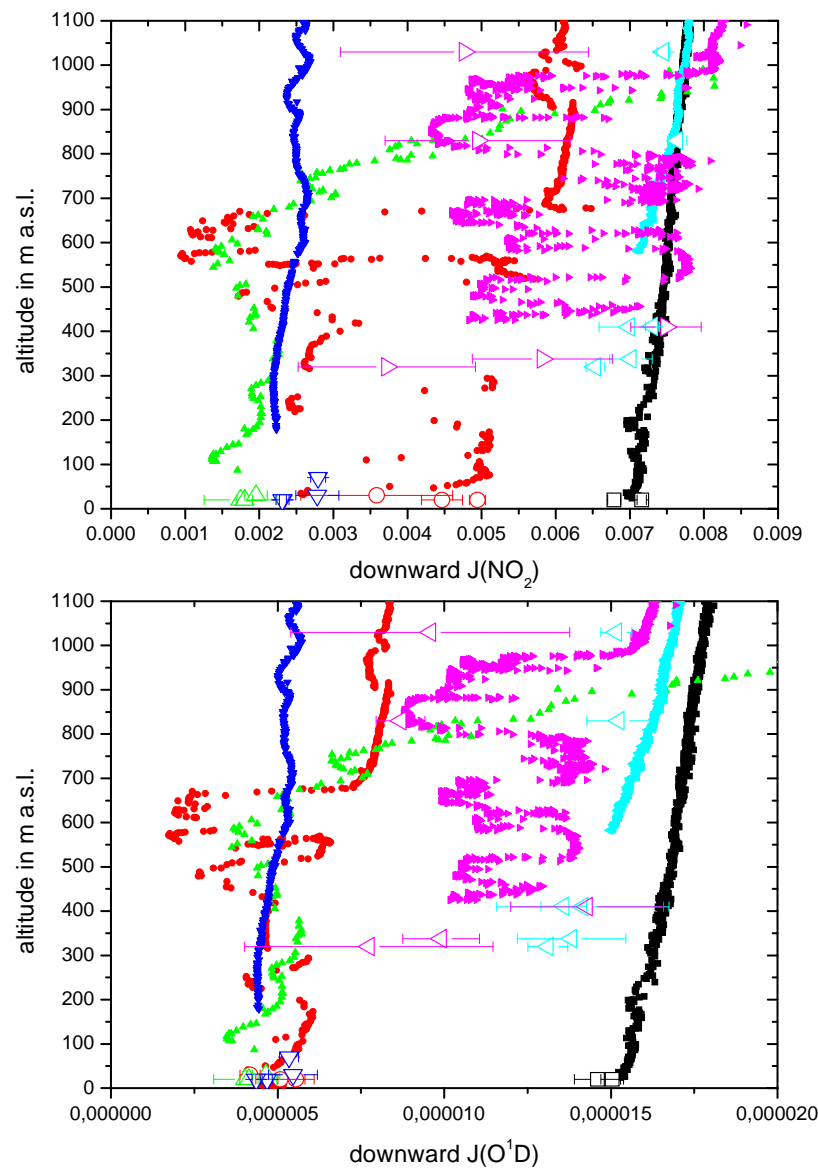

Fig. 9. Comparison of ground based and airborne measurements of downward actinic flux density. The selected days of the campaigns (sky condition) are marked in different colours: black - 12 September 2002 (clear sky), red - 13 September 2002 (scattered clouds), green - 14 September 2002 (overcast), blue - 15 September 2002 (overcast), turqoise - 20 May 2004 (clear sky), magenta - 26 May 2004 (partly cloudy). The groundbased measurements are represented by symbols with an error bar (standard deviation) which reflects the variability of the actinic flux density at the site during the flight period.

from the different altitudes of the sites. Both profiles show good agreement within the uncertainty limits of the measurement. But the measurements of the Brotjacklriedel site tend to be lower than the corresponding values of the airborne profile which can be explained by horizontal degradations at the site.

The comparison of measured and simulated actinic flux density (profiles and ground-based data) under cloudy conditions is described in more detail in Monks et al. (2004) and Kylling et al. (2005). Kylling et al. showed that for overcast days 1-D-radiative transfer calculations reproduce the overall behaviour of the actinic flux density measured by the aircraft. Furthermore the actinic flux density is increased by between 60-100\% above the cloud layer compared to a cloudless sky with the largest increase for the optically thickest cloud. The below-cloud actinic flux density is decreased by about 55$65 \%$. Just below the cloud top the downwelling actinic flux density has a maximum which is seen in both the measurements and the model results. For broken clouds the traditional cloud fraction approximation is not able to simultaneously reproduce the measured above-cloud enhancement and below-cloud reduction in the actinic flux density (Kylling et al., 2005).

\section{Comparison of a simulated 3-D cloud field with obser- vations}

An example of a 3-D cloud field resulting from the CLABAUTAIR-method (see Sect. 4 - Generation of a 3-D cloud field) and its validation by observations is shown in Fig. 10 for the day 146 during the second campaign (25 May, 09:50 UTC) in Bavaria. The corresponding sky camera pictures at several measurement sites and a picture taken from the aircraft demonstrate that the simulated cloud field overall mirrors the cloudy conditions over the campaign area. This impression was supported by comparison of the mean altitude of cloud top and cloud base as well as the mean cloud amount of the simulated cloud field with observations at the ground. Figure 11 shows a generally good agreement between the simulated and the mean of the time averaged cloud altitudes observed at the measurement sites Fürstenzell and Straubing. For most days of the campaign where it was possible to simulate the cloud situation the simulated cloud base lies within the variance limits of the ground based observations. The observed results represent an average over the time window of $\pm 0.5 \mathrm{~h}$ around 09:30 UTC. For the cloud top altitude it seems that the observations at the ground were systematically lower than the results of the simulated cloud field. This can be explained by an underestimation of the cloud top altitude by the observer. The agreement between the CLABAUTAIR simulations and observations of the real cloud field was much better during the second campaign than during the first campaign. The main reason for this was a changed flight pattern which was used during the second campaign. The tracks of that flight pattern were randomly distributed over the measurement area instead of a fixed track around the investigated area during the first campaign. Table 1 shows the mean cloud cover of the measurement area calculated from the simulated cloud field and results obtained by ground based and spaceborne observations. During the first four days of the first campaign the cloud amount of the simulated cloud field agrees with the observations made at Weybourne but shows a deviation to the European Cloud Climatology data set on day 258. On day 265 the calculated mean cloud amount was clearly lower than the observed values and on day 271 to high compared to the observations. On day 271 the cloud cover from the ECC data set was too low. This can be explained by the fact that the satellite overpass 


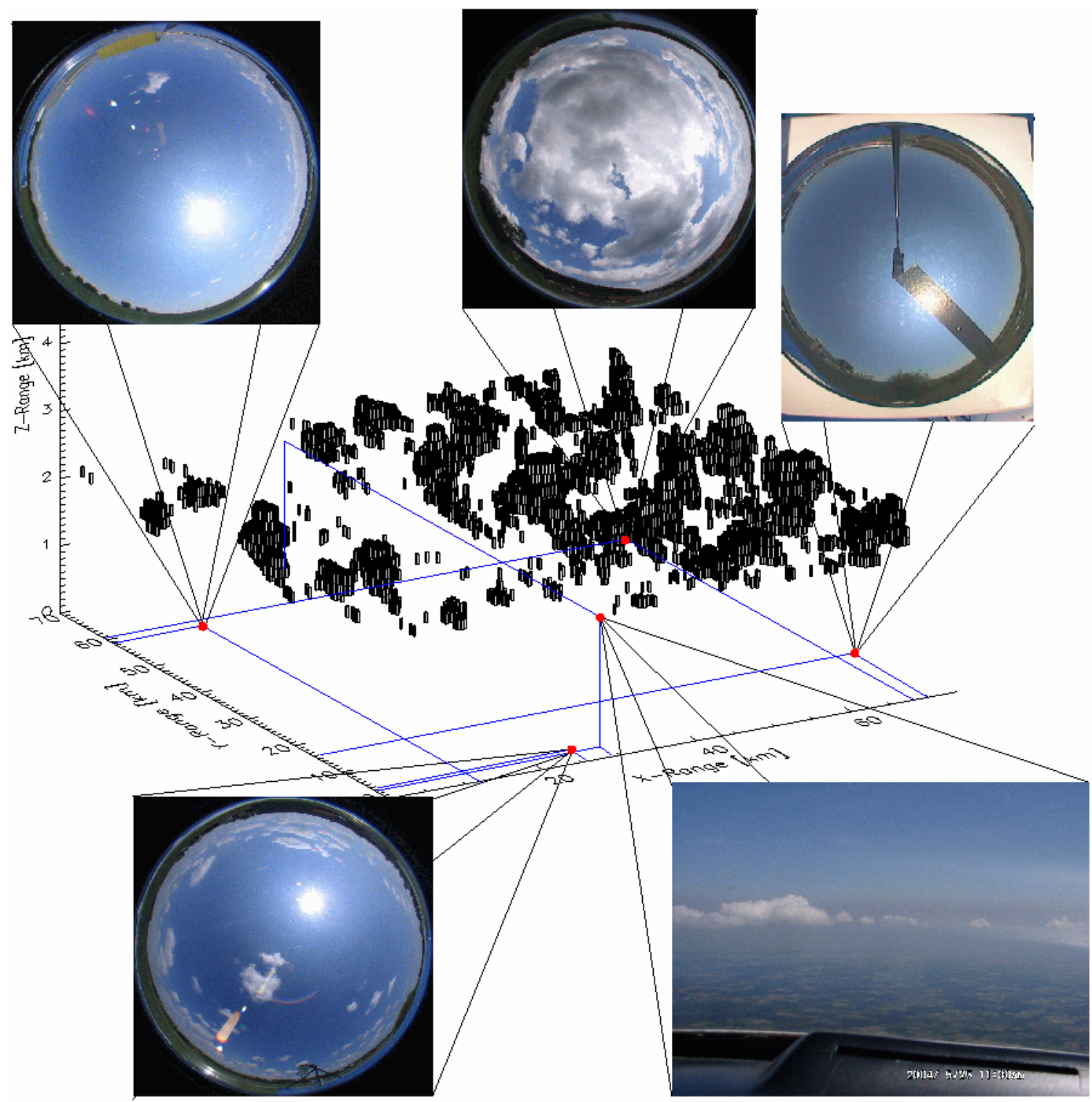

Fig. 10. Comparison of the structure of the simulated cloud field with observations made by eye at different sites on 25 May 2004 , at 09:30 UTC. Considering the high dynamical process of convective cloud development the simulated cloud field shows a good agreement with observed conditions may with the exception of Fürstenzell (upper line, last picture).

time is in most cases out of the time window of the aircraft measurements of liquid water content and effective radius on which the mean cloud cover of the simulated cloud field base and, therefore, a change in cloud cover out of this window was not considered.

Figure 12 shows results from three-dimensional radiation transfer calculations using the MYSTIC model and ground based measurements during the flight on 25 May 2004 of the second campaign in Bavaria. Considering the experiences gained during the first campaign, the regular triangular flight pattern had been replaced by a more random one which allowed better retrieval of the actual cloud structure. For such a large domain, the time-dependent cloud amount needs to be taken into account: During the flights the cloud-fraction increased remarkably. The retrieved cloud-field is thus a cross section along the increasing cloudiness. The comparison of
Fig. 12 shows the resulting normalised fluxes of all five stations and the simulated area-mean, standard deviations, and extreme values.

The difference between the observations at the individual sites illustrates the variability within the domain. While the actinic flux density at the Buchhofen station is very close to the cloudless sky simulation, the sky at Spiegelau was overcast after 09:00 UTC, probably caused by orographic clouds forming at the mountain. Nevertheless, the range of simulated values matches nicely the observations. In particular the lowest values of the simulation agree almost perfectly with the lowest observed data. On the other hand, the enhancement predicted by the model is somewhat larger than the enhancement observed at Spiegelau, Buchhofen, and Eggenfelden. 
Table 1. Cloud amount data (fractional area coverage) of the measurement area obtained from a simulated cloud field compared to ground based and satellite based observations of the corresponding real cloud field. The simulated cloud field is created with CLABAUTAIR and bases on airborne measurements of microphysical parameters of the real cloud field (liquid water content, effective radius). The satellite data is obtained from the European Cloud Climatology (ECC) data set (Meerkötter et al., 2004). The ground based observation by eye is represented by the mean cloud amount and its variability within the time window of the aircraft measurements for the cloud field simulation.

\begin{tabular}{llllll}
\hline $\begin{array}{l}\text { Day of } \\
\text { the year }\end{array}$ & $\begin{array}{l}\text { Time } \\
\text { window }\end{array}$ & $\begin{array}{l}\text { Simulated } \\
\text { Cloud Field }\end{array}$ & $\begin{array}{l}\text { Ground based } \\
\text { observation }\end{array}$ & ECC data & $\begin{array}{l}\text { ECC - Satellite } \\
\text { overpass time }\end{array}$ \\
\hline \multicolumn{7}{c}{ First campaign, East Anglia, 2002 } \\
\hline 256 & $09: 00-10: 00$ & 0.47 & $0.47 \pm 0.19$ & 0.64 & $11: 29$ \\
257 & $09: 55-12: 39$ & 1 & $1 \pm 0$ & 1.00 & $11: 18$ \\
258 & $09: 30-11: 30$ & 1 & $1 \pm 0$ & 0.71 & $12: 47$ \\
263 & $12: 32-14: 17$ & 0.99 & $1 \pm 0$ & 0.97 & $11: 52$ \\
265 & $12: 33-14: 47$ & 0.21 & $0.59 \pm 0.11$ & 0.49 & $11: 30$ \\
271 & $09: 24-11: 21$ & 0.71 & $0.39 \pm 0.16$ & 0.09 & $12: 04$ \\
\hline & & Second campaign, Bavaria, 2004 & \\
\hline 140 & $09: 09-11: 56$ & 0.78 & $0.31 \pm 0.08$ & 0.17 & $14: 31$ \\
145 & $10: 45-12: 01$ & 0.63 & $0.63 \pm 0.21$ & $0.56 \pm 0.07$ & $10: 15 / 14: 09$ \\
$146 a$ & $08: 16-11: 00$ & 0.14 & $0.25 \pm 0.21$ & - & - \\
$146 \mathrm{~b}$ & $11: 40-14: 25$ & 0.43 & $0.56 \pm 0.16$ & 0.66 & $13: 45$ \\
\hline
\end{tabular}

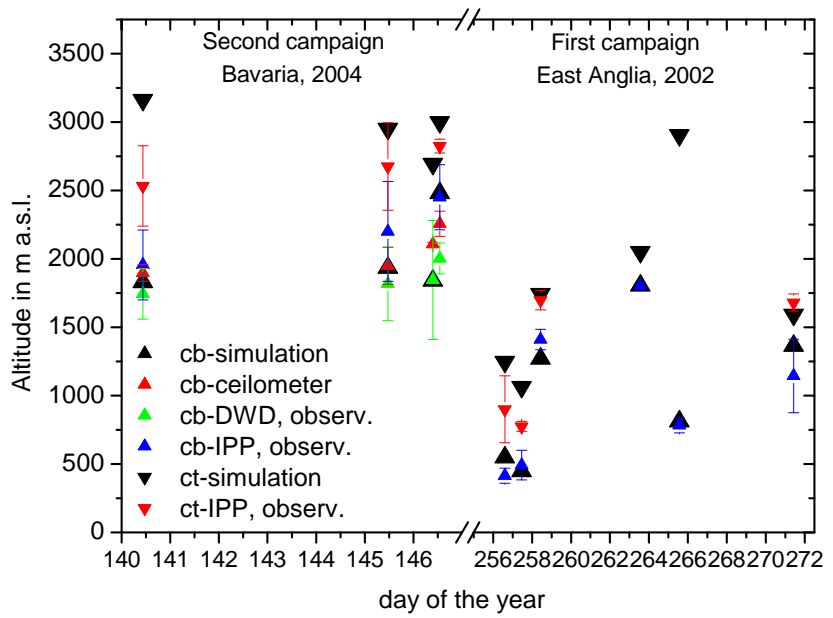

Fig. 11. Comparison of cloud base and cloud top altitudes of the simulated cloud field with observations made of the corresponding real cloud field. The simulated cloud field is created by the CLABAUTAIR algorithm which uses airborne liquid water content measurements. The observations are based on measurements by lidar, ceilometer and eye observation. DWD: German Weather Service, IPP: INSPECTRO project partner, cb: cloud base, ct: cloud top.

\section{Conclusions}

The method developed in the INSPECTRO project, to derive three-dimensional cloud structures from aircraft and satellite observations has been shown to provide realistic data, with respect to absolute numbers as well as statistical variability. For a real validation in the sense that input (clouds and atmosphere) as well as output (actinic flux density) were determined with high enough accuracy to decide if the simulations are "correct" within certain error limits, the observations were not sufficient. This is a general problem in cloudradiation research, due to the high variability of clouds in space and time of which we were well aware when the INSPECTRO proposal was prepared. A real "closure study" would require the most sophisticated equipment available, possibly a combination of scanning radar and lidar. Nevertheless, we conclude that the aim, to provide consistent cloud/radiation data sets for further analyses on the accuracy of various radiative transfer approximations and on atmospheric chemistry, was fully reached.

The intercomparison of all spectroradiometer systems during both campaigns confirmed an agreement of all systems within the range of $\pm 10 \%$ if necessary corrections e.g. stray light correction were applied. The changes in the stability were lower than $5 \%$ throughout the campaign period and even negligible during a few days. The $\mathrm{J}\left(\mathrm{O}^{1} \mathrm{D}\right)$ data of the single monochromator systems should not be used for zenith angles above $70^{\circ}$.

For cloudless conditions we can conclude that it is possible to reproduce the measurements of the actinic flux density profiles by a 1-D- radiative transfer model within the measurement and model uncertainties of about $\pm 10 \%$. The same order of deviation can be observed if the measurements between different spectroradiometer systems at the different aircraft are compared. 


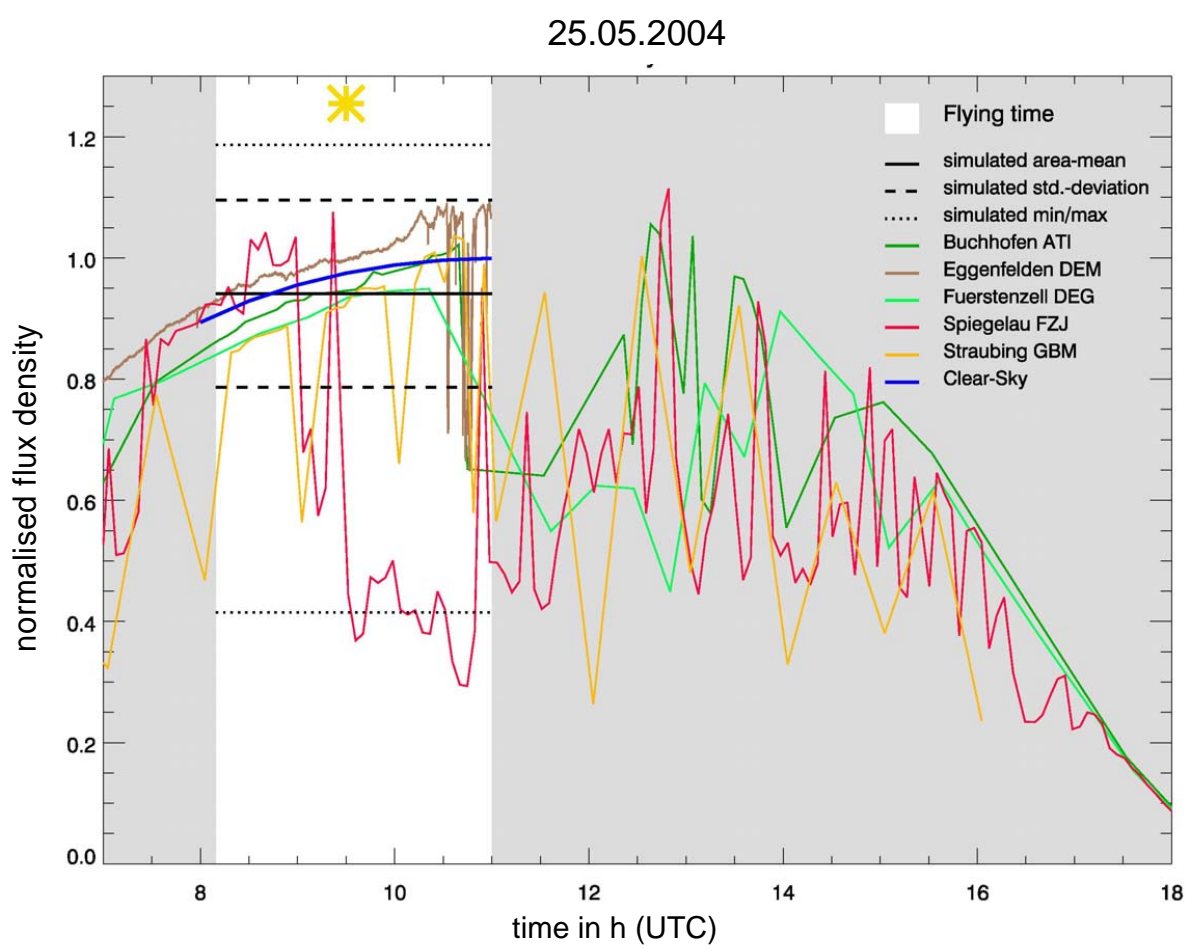

Fig. 12. Comparison of ground based measurements and 3-D-calculations from the radiation transfer model MYSTIC on 25 May 2004 in Bavaria (second campaign). The radiative transfer calculations were done for 09:30 UTC (yellow star). The calculated mean actinic flux density is averaged over the measurement area (black line) and represents the simulation during the complete flying period. The simulations agree well with the ground based observations during the flying period with respect to the calculated mean and its variability within the measurement area.

We further conclude that the cloud/radiation data sets obtained during INSPECTRO are very well suited for the study of the impact of cloud inhomogeneity on actinic flux density and atmospheric chemistry. They are among the most detailed, best characterized, and most validated data sets available worldwide. The data set is stored on the NILU data base but not yet publicly available as the research groups analysis of the data is ongoing. However, the usage of the data set is possible after contacting the authors.

Acknowledgements. This research was funded by contract EVK2CT-2001-00130 from the European Commission. Funding by the German Science Foundation (DFG) and the German Research Ministry (BMBF) are acknowledged. We thank the pilots of the Partenavia aircrafts, B. Schumacher and G. Vogl, as well as I. Stromberg, the Pilot of the Cessna during the first campaign. They all did an excellent job in preparing and conducting the measurements with their aircrafts. The participation of the QASUME spectroradiometer was partly financed by contract EVR1-CT2001-40011.

Edited by: A. Hofzumahaus

\section{References}

Abreu, L. W. and Anderson, G. P.: The MODTRAN 2/3 Report and LOWTRAN 7 Model, Prepared by Ontar Corporation for PL/GPOS, 1996.

Anderson, G., Clough, S., Kneizys, F., Chetwynd, J., and Shettle, E.: AFGL atmospheric constituent profiles (0$120 \mathrm{~km}$ ), Tech.Rep. AFGL-TR-86-0110, Air Force Geophys. Lab., Hanscom Air Force Base, Bedford, Mass., 1986.

Bais, A. F., Zerefos, C. S., and McElroy, C. T.: Solar UVB measurements with the double- and single- monochromator Brewer ozone spectrophotometers, Geophys. Res. Lett., 23(8), 833-836, 1996.

Bais, A. F., Madronich, S., Crawford, J., Hall, S. R., Mayer, B., van Weele, M., Lenoble, J., Calvert, J. G., Cantrell, C. A., Shetter, R. E., Hofzumahaus, A., Koepke, P., Monks, P. S., Frost, G., McKenzie, R., Krotkov, N., Kylling, A., Swartz, W. H., Lloyd, S., Pfister, G., Martin, T. J., Roeth, E. P., Griffioen, E., Ruggaber, A., Krol, M., Kraus, A., Edwards, G. D., Mueller, M., Lefer, B. L., Johnston, P., Schwander, H., Flittner, D., Gardiner, B. G., Barrick, J., and Schmitt, R.: International Photolysis Frequency Measurement and Model Intercomparison (IPMMI): Spectral actinic solar flux measurements and modelling, J. Geophys. Res.Atmos., 108(D16), 8543-8543, 2003.

Balis, D. S., Zerefos, C. S., Kourtidis, K., Bais, A. F., Hofzumahaus, A., Kraus, A., Schmitt, R., Blumthaler, M., and Gobbi, G. P.: Measurements and modeling of photolysis rates during the Pho- 
tochemical Activity and Ultraviolet Radiation (PAUR) II campaign, J. Geophys. Res.-Atmos., 107(D18), 8138-8138, 2002.

Barnaba, F. and Gobbi, G. P.: Lidar estimation of tropospheric aerosol extinction, surface area and volume: Maritime and desert-dust cases, J. Geophys. Res., 106(D3), 3005-3018, 2001.

Barnaba F. and Gobbi, G. P.: Modeling the aerosol extinction versus backscatter relationship in a mixed maritime-continental atmosphere: Lidar application and validation, J. Atmos. Ocean. Technol., 21, 428-442, 2004.

Bass, A. M. and Paur, R. J.: The ultraviolet cross-section of ozone, I The measurements, in Atmospheric Ozone: Proceedings of the Quadrennial Ozone Symposium, edited by: Zerefos, C. S. and Ghazi, A., 601-606, D. Reidel, Norwell, Mass., 1985.

Bernhard, G. and Seckmeyer, G.: New Entrance Optics for Solar Spectral UV Measurements, Photochemistry and Photobiology, 65(6), 923-930, 1997.

Bernhard, G. and Seckmeyer, G.: Uncertainty of measurements of spectral solar UV irradiance, J. Geophys. Res., 104(D12), 14 321-14345, 1999.

Bodhaine, B. A., Wood, N. B., Dutton, E. G., and Slusser, J. R.: On Rayleigh Optical Depth Calculations, J. Atmos. Ocean Technol., 16, 1854-1861, 1999.

Bohn, B., Kraus, A., Müller, M., and Hofzumahaus, A.: Measurement of atmospheric $\mathrm{O}_{3}->\mathrm{O}\left({ }^{1} \mathrm{D}\right)$ photolysis frequencies using filterradiometry, J. Geophys. Res., 109(D16), D10S90, doi:10.1029/2003JD004319, 2004.

Crawford, J., Shetter, R. E., Lefer, B., Cantrell, C., Junkermann, W., Madronich, S., and Calvert, J.: Cloud impacts on UV spectral actinic flux observed during the International Photolysis Frequency Measurement and Model Intercomparison (IPMMI), J. Geophys. Res.-Atmos., 108(D14), 8545, doi:10.1029/2002JD002731, 2003.

Daumont, D., Brion, J., Charbonnier, J., and Malicet, J.: Ozone UV spectroscopy: I. Absorption cross-sections at room temperature, J. Atmos. Chem., 15, 145-155, 1992.

Fleming, Z. L., Monks, P. S., Rickard, A. R., Bandy, B. J., Brough, N., Green, T. J., Reeves, C. E., and Penkett, S. A.: Seasonal dependence of peroxy radical concentrations at a Northern hemisphere marine boundary layer site during summer and winter: evidence for radical activity in winter, Atmos. Chem. Phys., 6, 5415-5433, 2006, http://www.atmos-chem-phys.net/6/5415/2006/.

Gobbi, G. P., Barnaba, F., and Ammannato, L.: The vertical distribution of aerosols, Saharan dust and cirrus clouds at Rome (Italy) in the year 2001, Atmos. Chem. Phys., 4, 351-359, 2004, http://www.atmos-chem-phys.net/4/351/2004/.

Gröbner, J., Schreder, J., Kazadzis, S., Bais, A. F., Blumthaler, M., Gorts, P., Tax, R., Koskela, T., Seckmeyer, G., and Webb, A. R.: A travelling reference spectroradiometer for routine quality assurance of spectral solar ultraviolet irradiance measurements, Appl. Optics, 44, 25, 5321-5331, 2005.

Gröbner, J., Blumthaler, M., Kazadzis, S., Bais, A., Webb, A., Schreder, J., Seckmeyer, G., and Rembges, D.: Quality Assurance of spectral solar UV measurements: Results from $26 \mathrm{UV}$ monitoring sites in Europe, 2002 to 2004, Metrologia, 43, 6671, 2006.

Green, T. J., Reeves, C. E., Fleming, Z. L., Brough, N., Rickard, A. R., Bandy, B. J., Monks, P. S., and Penkett, S. A.: An improved dual channel PERCA instrument for atmospheric measurements of peroxy radicals, J. Environ. Monitoring, 8(5), 530-536, 2006.

Hansen, J. E. and Travis, L. D.: Light scattering in planetary atmospheres, Space Sci. Rev., 16, 527-610, 1974.

Hofzumahaus, A., Kraus, A., and Müller, M.: Solar actinic flux spectroradiometry: A technique for measuring photolysis frequencies in the atmosphere, Appl. Optics, 38, 4443-4460, 1999.

Hofzumahaus, A., Kraus, A., Kylling, A., and Zerefos, C.: Solar actinic radiation $(280-420 \mathrm{~nm})$ in the cloud-free troposphere between ground and $12 \mathrm{~km}$ altitude: Measurements and model results, J. Geophys. Res., 107, 8139, doi:10.1029/2001JD900142, 2002.

Jäkel, E., Wendisch, M., Kniffka, A., and Trautmann, T.: A new airborne system for fast measurements of up- and downwelling spectral actinic flux densities, Appl. Optics, 44(3), 434-444, 2005.

Jäkel, E., Wendisch, M., Blumthaler, M., Schmitt, R., and Webb, A.: A CCD spectroradiometer for ultraviolet actinic radiation measurements, J. Atmos. Oceanic Technol., 24(3), 449-462, 2007.

Junkermann, W., Platt, U., and Volz, A.: A Photoelectric Detector of the Measurement of Photolysis Frequencies of Ozone and other Atmospheric Molecules, J. Atmos. Chem., 8, 203-227, 1989

Junkermann, W.: The actinic UV-radiation budget during the ESCOMPTE campaign 2001: Results of airborne measurements with the microlight research aircraft D-MIFU, Atmos. Res., 74, 461-475, doi:10.1016/j.atmosres.2004.06.0 09, 2005

Kazadzis, S., Bais, A. F., Kouremeti, N., Gerasopoulos, E., Garane, K., Blumthaler, M., Schallhart, B., and Cede, A.: Direct spectral measurements with a Brewer spectroradiometer: absolute calibration and aerosol optical depth retrieval, Appl. Optics, 44, 1681-1690, 2005.

Keil, A., Wendisch, M., and Brügemann, E.: Measured profiles of aerosol particle absorption and its influence on clear-sky solar radiative forcing, J. Geophys. Res., 106, 1237-1247, 2001.

Kriebel, K.-T., Gesell, G., Kästner, M., and Mannstein, H.: The cloud analysis tool APOLLO: improvements and validation, Int. J. Remote Sensing, 24, 12, doi:10.1080/01431160210163065, 2003.

Kylling, A., Webb, A. R., Kift, R., Gobbi, G. P., Ammannato, L., Barnaba, F., Bais, A., Kazadzis, S., Wendisch, M., Jakel, E., Schmidt, S., Kniffka, A., Thiel, S., Junkermann, W., Blumthaler, M., Silbernagl, R., Schallhart, B., Schmitt, R., Kjeldstad, B., Thorseth, T. M., Scheirer, R., and Mayer, B.: Spectral actinic flux in the lower troposphere: measurement and 1-D simulations for cloudless, broken cloud and overcast situations, Atmos. Chem. Phys., 5, 1975-1997, 2005, http://www.atmos-chem-phys.net/5/1975/2005/.

Lelieveld, J. and Crutzen, P. J.: The role of clouds in tropospheric photochemistry, J. Atmos. Chem., 12, 229-267, 1991.

Los, A., van Weele, M., and Duynkerke, P. G.: Actinic fluxes in broken cloud fields, J. Geophys. Res., 102, 4257-4266, 1997.

Madronich, S.: Photodissociation in the atmosphere: I. Actinic flux and the effects of ground reflections and clouds, J. Geophys. Res., 92, 9740-9752, 1987.

Marenco F., Santacesaria, V., Bais, A. F., Balis, D., di Sarra, A., Papayannis, A., and Zerefos, C.: Optical properties of tropospheric aerosols determined by lidar and spectrophotometric measurements Photochemical Activity and Solar Ultraviolet Radiation campaign, Appl. Optics, 36, 6875-6886, 1997.

Matsumi, Y., Comes, F. J., Hancock, G., Hofzumahaus, A., Hynes, 
A. J., Kawasaki, M., and Ravishankara, A. R.: Quantum yields for production of $\mathrm{O}(1 \mathrm{D})$ in the ultraviolet photolysis of ozone: Recommendation based on evaluation of laboratory data, J. Geophys. Res., 107(D3), 4024, doi:10.1029/2001JD000510, 2002.

Mayer, B.: I3RC phase 2 results from the MYSTIC Monte Carlo model. Extended abstract for the I3RC (Intercomparison of 3D radiation codes) workshop, Tucson, Arizona, November 15-17, available at http://i3rc.gsfc.nasa.gov, 2000

Mayer, B. and Madronich, S.: Actinic flux and photolysis in water droplets: Mie calculations and geometrical optics limit, Atmos. Chem. Phys., 4, 2241-2250, 2004,

http://www.atmos-chem-phys.net/4/2241/2004/.

Mayer, B. and Kylling, A.: Technical note: The libRadtransoftware package for radiative transfer calculations - description and examples of use, Atmos. Chem. Phys., 5, 855-1877, 2005,

http://www.atmos-chem-phys.net/5/855/2005/.

Meerkötter, R., König, C., Bissolli, P., Gesell, G., and Mannstein, H.: A 14-year European Cloud Climatology from NOAA/AVHRR data in comparison to surface observations, Geophys. Res. Lett., 31, L15103, doi:10.1029/2004GL020098, 2004.

Meloni, D., diSarra, A., Fiocco, G., and Junkermann, W.: Tropospheric aerosols in the Mediterranean: III: measurements and modelling of actinic radiation profiles, J. Geophys. Res., 108(D10), 4323, doi:10.1029/2002JD003293, 2003.

Menut, L., Flamant, C., Pelon, J., and Flamant, P. H.: Urban boundary layer height determination from lidar measurements over the Paris area, Appl. Optics, 38, 945-954, 1999.

Merienne, M. F., Jenouvrier, A., and Coquart, B.: The $\mathrm{NO}_{2}$ absorption spectrum I: Absorption cross-sections at ambient temperature in the 300-500 nm region, J. Atmos. Chem., 20, 281-297, 1995.

Mims, F. M. and Frederick, L. E.: Cumulus clouds and UV-B, Nature, 371 (6495), 291, 1994.

Monks, P. S., Rickard, A. R., Hall, S. L., and Richards, N. A. D.: Attenuation of spectral actinic flux and photolysis frequencies at the surface through homogenous cloud fields, J. Geophys. Res.Atmos., 109(D17), D17206, doi:10.1029/2003JD004076, 2004.

Nack, M. L. and Green, A. E. S.: Influence of clouds, haze, and smog on the middle ultraviolet reaching the ground, Appl. Optics, 12, 2405-2415, 1974.

Penkett, S. A., Plane, J. M. C., Comes, F. J., Clemitshaw, K. C., and Coe, H.: The Weybourne atmospheric observatory, J. Atmos. Chem., 33, 107-110, 1999.

Rahman, H., Pinty, B., and Verstraete, M. M.: Coupled SurfaceAtmosphere Reflectance (CSAR) Model 2. Semiempirical Surface Model Usable With NOAA Advanced Very High Resolution Radiometer Data, J. Geophys. Res., 98(D11), 20791-20 801, 1993.

Scheirer, R. and Schmidt, S.: CLABAUTAIR: a new algorithm for retrieving three dimen-sional cloud structure from airborne microphysical measurements, Atmos. Chem. Phys., 5, 2333-2340, 2005 ,

http://www.atmos-chem-phys.net/5/2333/2005/.

Schmidt, S., Venema, V., Di Giuseppe, F., Scheirer, R., Wendisch, M., and Pilewskie, P.: Reproducing cloud microphysical and irradiance measurements using three $3 \mathrm{D}$ cloud generators, Q. J. Roy. Meteorol. Soc., 133, 765-780, 2007.

Schreder, J., Blumthaler, M., and Huber, M.: Design of an input optic for solar UV-measurements; Protection against the Hazards of UVR, Internet Photochemistry and Photobiology (http://www. photobiology.com/UVR98/schreder/index.htm), 1998.

Seckmeyer, G., Erb, R., and Albold, A.: Transmittance of a cloud is wavelength-dependent in the UV-range, Geophys. Res. Lett., 23, 2753-2755, 1996.

Shettle, E. P.: Models of aerosols, clouds, and precipitation for atmospheric propagation studies, AGARD Conf. Proc., 454, 1532, 1989.

Shetter, R. E. and Müller, M.: Photolysis frequency measurements using actinic flux spectroradiometry during the PEM-Tropics mission: instrumentation description and some results, J. Geophys. Res., 104, 5647-5661, 1999.

Shetter, R. E., Cinquini, L., Lefer, B. L., Hall, S. R., and Madronich, S.: Comparison of airborne measured and calculated spectral actinic flux and derived photolysis frequencies during the PEM Tropics B mission, J. Geophys. Res.-Atmos., 108(D2), 8234 8234, 2002.

Slaper, H., Reinen, H. A. J., Blumthaler, M., Huber, M., and Kuik, F.: Comparing ground-level spectrally resolved solar UV measurements using various instruments: A technique resolving effects of wavelengths shift and slit width, Geophys. Res. Lett., 22, 2721-2724, 1995.

Stamnes, K., Tsay, S.-C., Wiscombe, W., and Jayaweera, K.: Numerically stable algorithm for discrete-ordinate-method radiative transfer in multiple scattering and emitting layered media, Appl. Optics, 27, 2502-2509, 1988.

Thompson, A. M. and Stewart, R. W.: Effect of Chemical Kinetics Uncertainties on Calculated Constituents in an Tropospheric Photochemical Model, J. Geophys. Res., 96, 13 089-13 108, 1991.

Trautmann, Th., Podgorny, I., Landgraf, J., and Crutzen, P. J.: Actinic fluxes and photodissociation coefficients in cloud fields embedded in realistic atmospheres, J. Geophys. Res., 104, $30153-$ $30172,1999$.

Troe, J.: Are primary quantum yields of NO2 photolysis at lambda $<=398 \mathrm{~nm}$ smaller than unity?, Zeit. Phys. Chem., 214, 573$581,2000$.

Tukey, J. W.: Exploratory Data Analysis, Addison-Wesley, 1977.

Van Hoosier, M. E.: The ATLAS-3 solar spectrum, Naval Research Laboratory, Washington, D.C., available via ftp://susim.nrl.navy. mil/pub/atlas3, 1996.

Volz-Thomas, A., Lerner, A., Pätz, H.-W., Schultz, M., McKenna, D. S., Schmitt, R., Madronich, S., and Röth, E. P.: Airborne measurements of the photolysis frequency of $\mathrm{NO}_{2}$, J. Geophys. Res., 101(D13), 18 613-18627, 1996.

Webb, A. R., Stromberg, I. M., Li, H., and Bartlett, L. M.: Airborne spectral measurements of surface reflectivity at ultraviolet and visible wavelengths, J. Geophys. Res.-Atmos., 105(D4), 49454948, 2000.

Webb, A. R., Bais, A. F., Blumthaler, M., Gobbi, G.-P., Kylling, A., Schmitt, R., Thiel, S., Barnaba, F., Danielsen, T., Junkermann, W., Kazantzidis, A., Kelly, P., Kift, R., Liberti, G. L., Misslbeck, M., Schallhart, B., Schreder, J., and Topaloglou, C.: Measuring spectral actinic flux and irradiance: Experimental results from the ADMIRA (Actinic Flux Determination from Measurements of Irradiance), J. Atmos. Ocean Technol., 19, 1049-1062, 2002.

Webb, A. R., Kylling, A., Stromberg, I. M., Jäkel, E., and Wendisch, M.: Airborne measurements of ground and cloud 
spectral albedo, J. Geophys. Res.-Atmos., 109(D20), D20205, doi:10.1029/2004JD004768, 2004.

Wendisch, M., Müller, D., Schell, D., and Heintzenberg, J.: An airborne spectral albedometer with active horizontal stabilization, J. Atmos. Ocean Technol., 18, 1856-1866, 2001.

Wendisch, M. and Mayer, B.: Vertical distribution of spectral solar irradiance in the cloudless sky - A case study, Geophys. Res. Lett., 30, 1183-1186, doi:10.1029/2002GL016529, 2003.
Wendisch, M., Pilewskie, P., Jäkel, E., Schmidt, S., Pommier, J., Howard, S., Jonsson, H. H., Guan, H., Schröder, M., and Mayer, B.: Airborne measurements of areal spectral surface albedo over different sea and land surfaces, J. Geophys. Res., 109(D08), 203, doi:10.1029/2003JD004393, 2004. 